\title{
Performance and Evaluation of Gas-Engine-Driven Rooftop Air Conditioning Equipment at the Willow Grove Naval Air Station
}

Final Report (Revised 10-21-96)

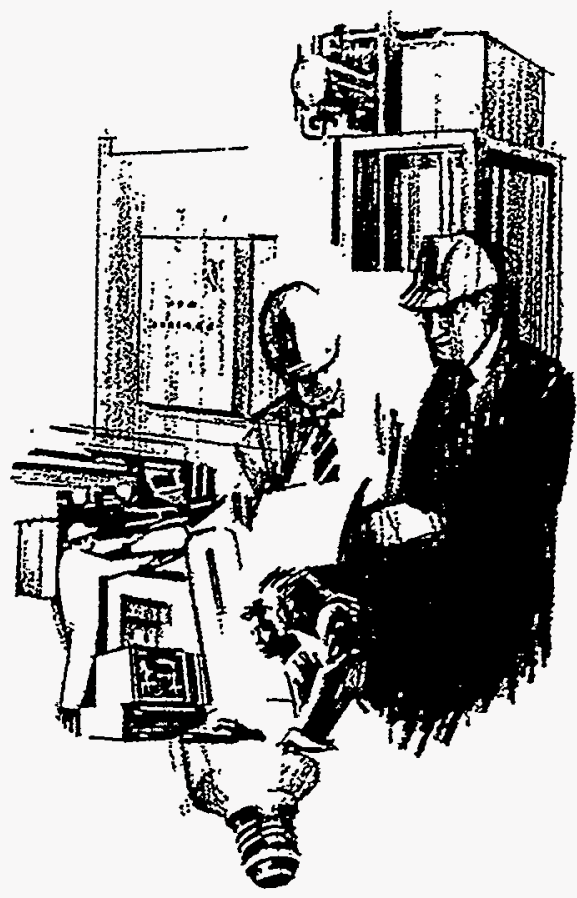

October 1996

Prepared for the U.S. Department of Energy

Federal Energy Management Program under Contract DE-AC06-76RLO 1830

Pacific Northwest National Laboratory Operated for the U.S. Department of Energy by Battelle Memorial Institute

\section{Battelle}




\title{
DISCLAIMER
}

This report was prepared as an account of work sponsored by an agency of the United States Government. Neither the United States Government nor any agency thereof, nor Battelle Memorial Institute, nor any of their employees, makes any warranty, express or implied, or assumes any legal liability or responsibility for the accuracy, completeness, or usefulness of any information, apparatus, product, or process disclosed, or represents that its use would not infringe privately owned rights. Reference herein to any specific commercial product, process, or service by trade name, trademark, manufacturer, or otherwise does not necessarily constitute or imply its endorsement, recommendation, or favoring by the United States Government or any agency thereof, or Battelle Memorial Institute. The views and opinions of authors expressed herein do not necessarily state or reflect those of the United States Government or any agency thereof.

\author{
PACIFIC NORTHWEST NATIONAL LABORATORY \\ operated by \\ BATTELLE \\ for the \\ UNITED STATES DEPARTMENT OF ENERGY \\ under Contract DE-AC06-76RLO 1830
}

Printed in the United States of America

Available to DOE and DOE contractors from the Office of Scientific and Technical Information, P.O. Box 62, Oak Ridge, TN 37831; prices available from (615) 576-8401.

Available to the public from the National Technical Information Service, U.S. Department of Commerce, 5285 Port Royal Rd., Springfield, VA 22161 


\section{Performance and Evaluation of Gas-Engine-} Driven Rooftop Air-Conditioning Equipment at the Willow Grove Naval Air Station

Final Report (Revised 10-21-96)

P. R. Armstrong

S. Katipamula

October 1996

Prepared for

the U.S. Department of Energy

Federal Energy Management Program under Contract DE-AC06-76RLO 1830

Pacific Northwest National Laboratory

Richland, Washington 99352 


\section{DISCLAIMER}

This report was prepared as an account of work sponsored by an agency of the United States Government. Neither the United States Government nor any agency thereof, nor any of their employees, makes any warranty, express or implied, or assumes any legal liability or responsibility for the accuracy, completeness, or usefulness of any information, apparatus, product, or process disclosed, or represents that its use would not infringe privately owned rights. Reference herein to any specific commercial product, process, or service by trade name, trademark, manufacturer, or otherwise does not necessarily constitute or imply its endorsement, recommendation, or favoring by the United States Government or any agency thereof. The views and opinions of authors expressed herein do not necessarily state or reflect those of the United States Government or any agency thereof. 


\section{DISCLAIMER}

Portions of this document may be illegible in electronic image products. Images are produced from the best available original document. 


\section{Preface}

The federal government is the largest single energy consumer in the United States with consumption of nearly 1.5 quads/yr $\left(1\right.$ quad $\left.=10^{15} \mathrm{Btu}\right)$ and cost valued at nearly $\$ 10$ billion annually. The U.S. Department of Energy's (DOE) Federal Energy Management Program (FEMP) supports efforts to reduce energy use and associated expenditures within the federal sector. One such effort, the New Technology Demonstration Program (formerly the Test Bed Demonstration Program), seeks to evaluate new energy saving U.S. technologies and secure their more timely adoption by the federal government.

Through the results of a New Technology Demonstration Program, federal agency decision makers can receive more "hands on" information with which to validate the decision to utilize a new technology in their facilities. Energy saving technologies regularly emerge in the marketplace. This program seeks to identify those technologies, determine which have the broadest application for the federal sector, and then shorten the deployment time for those that prove beneficial to the federal market.

Recent initiatives within the federal government have focused on the use of natural gas for both economic and environmental reasons. It is therefore fitting that the technology selected for evaluation in the first new technology demonstration, and the subject of this report, is natural gas-engine-driven cooling equipment.

The project began with the solicitation of interested parties willing to participate in the installation and evaluation of gas cooling technologies. The search for a suitable federal site within the service areas of the responding utilities then commenced. By early 1992 the field had been narrowed to one manufacturer, Thermo King Corporation, and three utilities.

PECO Energy, one of the three interested utilities, determined that a naval facility within its service area had recently (fall of 1991) installed two of the Thermo King units. This provided an opportunity to quickly implement the first test bed demonstration, which became critical with the 1992 cooling season approaching.

Discussions were initiated with the site-the Naval Air Station at Willow Grove, PA-and other interested parties who had responded to the solicitation. These included the American Gas Cooling Center (AGCC), PECO Energy, and the Thermo King Corporation. Based on an evaluation of the building, utility costs, and past building performance, it was determined that the installation offered a good opportunity to evaluate the performance of the subject technology. A Cooperative Research and Development Agreement involving the foregoing parties, DOE, and PNNL was formalized to evaluate . the technology. 
As part of the agreement, the American Gas Association Laboratories, who had performed similar efforts on the equipment at other non-federal installations, was tasked to design the data acquisition system on behalf of PECO Energy and AGCC. At the beginning of the 1992 cooling season the data acquisition system was installed and commissioned. Operation of the units was monitored during the 1992-93 heating and cooling seasons, the monitored data were analyzed, and the results are reported herein.

During the 2-year period in which this gas-cooling technology was being evaluated at Willow Grove, Thermo King decided to sell its stationary air-conditioning assets to Trico Energy in order to focis on its primary markets in mobile air conditioning. As of November 1996, Trico Energy continues to produce equipment using Thermo King compressors and Hercules engines, as well as to develop new gas-cooling designs. 


\section{Executive Summary}

Through a Cooperative Research and Development Agreement (CRADA), the U.S. Department of -Energy Federal Energy Management Program (FEMP), Pacific Northwest National Laboratory, the American Gas Cooling Center, PECO Energy, Thermo King Corporation (TK), and the Naval Air Station at Willow Grove (NASWG) have evaluated the performance of a new U.S. cooling technology that has been installed for the first time at a federal facility.

The gas-engine-driven cooling technology selected for study by the New Technology Demonstration Program is a 15-ton natural gas-engine-driven rooftop air-conditioning unit manufactured by Thermo King Corporation. The equipment is air-cooled and serves a single zone for both heating and cooling. It is factory assembled, charged with R-22 (an HCFC refrigerant), and requires single point connections of electrical power (for the supply air fan motor) and natural gas. The unit's cooling capacity is 190,000 Btuh at ARI Standard 360 rating conditions. The unit's heating capacity is 216,000 Btuh output at 265,000 Btuh input. Variable engine speed allows for cooling operation in three stages and cylinder unloading provides an additional stage for light load conditions.

Two of the Thermo King units were installed to serve the Navy Exchange (NEX) at NASWG. The retail sales area of the building covers $12,500 \mathrm{ft}^{2}$ and was previously conditioned by two rooftop units using \#2 fuel oil for heating and conventional electric-motor-driven direct-expansion refrigeration for cooling. To evaluate the new technology, the building and the new gas-engine-driven units were instrumented and monitored.

Data collected during the demonstration included outdoor and indoor temperature and humidity, gas and electric consumption of the equipment, refrigerant pressures and temperatures, and operating time associated with different stages of the units. The measurements, generally averaged and recorded at the end of each 15-minute scan interval, were used to evaluate the equipment performance and energy use, and to diagnose operational problems.

The relation between cooling load and ambient temperature, and the relation between equipment coefficient of performance (COP = cooling effect/input energy) and load were characterized based on the recorded data. A number of problems associated with the operation of the equipment, and possible solutions, were also identified.

The input load was fairly well correlated with outside temperature. However, one unit used almost . twice as much fuel as the other unit. A small difference in the room temperature setpoints of the two units may have caused the load imbalance. Each of the two units has its own thermostat even though both units serve the same retail area of the NEX. This area would normally be considered a single zone. It might be more appropriate to control both units from a single thermostat with multiple temperature sensors to ensure load balance. 
The linear regression of input load with outside temperature indicated a daily gas consumption of $3,960 \mathrm{kBtu}$ per Fahrenheit degree above a mean daily temperature of $60^{\circ} \mathrm{F}$ on days that the BX was open. The cooling capacity of each unit is varied to meet load by changing engine/compressor shaft speed and (for the lowest stage) by unloading two of four compressor cylinders and changing indoor fan speed. Thus a unit can operate in one of four cooling stages designated $\mathrm{C} 1$ through $\mathrm{C} 4$. The nominal capacities are $25,000^{(\text {a) }}$ Btuh in stage $\mathrm{C1}, 84,000$ Btuh in stage 2, 143,000 Btuh in stage 3, and 190,000 Btuh in stage C4.

The coefficient of performance for unit 1 was computed from air-side sensible and latent loads and gas input energy rate. COP was relatively constant in each cooling stage, ranging between 0.5 and 0.6 in $\mathrm{C} 1$, between 0.8 and 1.0 in $\mathrm{C} 2$, between 0.65 and 0.75 in $\mathrm{C} 3$ and between 0.5 and 0.6 in $\mathrm{C} 4$. The overall daily COP was found to track the stage 1 (C1) COP on most days but to improve, because of the influence of $\mathrm{C} 2$ and $\mathrm{C} 3 \mathrm{COPs}$, on higher load days.

The measured COPs were compared to the COPs quoted by Thermo King (TK 1990, p 25). The C1 COP was almost double the quoted value, ${ }^{(b)}$ the $C 2$ COP was very close to the quoted value, and the $\mathrm{C} 3$ and $\mathrm{C4}$ COPs were both about $10 \%$ less than the quoted values.

The seasonal COP is, in simplest terms, the sum of the part-load COP and part-load operating time products divided by the total operating time. The seasonal COP for unit 1 is substantially lower then the integrated part-load value (IPLV) quoted, due mainly to longer operation in stage 1 and shorter operation in stage 2 relative to the IPLV shares of operating time assumed by the manufacturer.

The units consumed $190 \mathrm{MBtu}$ (HHV) of natural gas and provided $115 \mathrm{MBtu}$ of cooling effect during the 1992 monitoring/analysis period. The units burned $367 \mathrm{MBtu}$ (HHV) of fuel in the 1993 cooling season to provide approximately $217 \mathrm{MBtu}$ of cooling. They are expected to use $370 \mathrm{MBtu}$ of gas and provide $225 \mathrm{MBtu}$ of cooling in a normal cooling season.

The two units burned $159 \mathrm{MBtu}$ (HHV) of fuel in the 1992-93 heating season to provide $127 \mathrm{MBtu}$ of heating.

The new and unique nature of the equipment required extra care and support from experienced local service people. However the added cost, in terms of lost performance, was relatively minor. There were only two shutdowns that were directly related to the equipment. These were attributable to

(a) Two values of the first stage nominal capacity are possible depending on whether one or both sections of the evaporator are selected. With one section (25\% of face area) selected the nominal capacity is 26,000 Btuh; with both it is about 40,000 Btuh.

(b) The quoted COP was based on use of $1 / 4$ of the evaporator coil by means of a control valve that can be used to stop flow through the other $3 / 4$ of the coil in $C 1$. This valve was disabled (as is standard in all units manufactured after 4/92) in unit 1 . Hence the full coil was used, resulting in higher capacity at about the same shaft power (due to higher refrigerant flow but lower suction pressure) and higher COP. 
removal and replacement of the engine starter on one unit and a unit shutoff due to refrigerant pressure. Service for this installation will probably not be a problem in future years because the local service people are now familiar with the new technology. The growing market penetration that is currently underway nationally should ensure the availability of qualified local service in the future.

There appear to be opportunities for improving the seasonal cooling performance of the equipment by modifying the staging control sequence. There may be further opportunities for improving seasonal performance and reducing aggregate annual engine starts in multi-unit applications by coordinated and integrated control of the units. A multi-zone Rooftop Unit (RTU) configuration with the two RTUs feeding a single air distribution system would be appropriate at the Willow Grove BX.

The annual energy costs for cooling, based on the loads and performance measured during the 10 week monitoring period and weather normalized to the full cooling season in a normal year, are $\$ 2,450$ to operate the compressors and condenser fans in the two units. The annual energy costs to operate the compressors and condenser fans in comparable electric-powered units would be $\$ 1,040$ in energy charges and $\$ 14,380$ in demand and ratchet charges. Maintenance of the TK units is expected to cost about $\$ 400 / y r$ more than the maintenance of comparable electric-powered units. The technology will therefore save about $\$ 12,500$ in net O\&M costs in a normal weather year.

The units will use about the same amount of source energy ${ }^{(a)}$ for cooling as comparable electricpowered units. The operation of electric motor and gas-engine-driven units is very similar and the level of comfort provided by the two types of units is indistinguishable.

The net savings for the gas-engine-driven unit is the difference between the present value of savings, $\$ 148,023$, and the increased total investment of $\$ 26,642$. This gives a net LCC savings, expressed as a present value, of $\$ 121,381$. The net savings-to-investment ratio is 5.56 assuming the previous electric units had to be replaced anyway at the time of the retrofit.

In cases where the existing electrical equipment is not worn out, the net savings-to-investment ratio would be less, but it is still favorable (1.90) even for the hypothetical case of replacing brand new electric equipment, given the rate structure and load distributions at Willow Grove.

Analysis of 240 federal sites indicates that the new technology is life-cycle cost-effective at sites representing about $6 \%$ of the installed federal-sector cooling capacity and over $5 \%$ of the aggregate annual cooling load. Assuming that gas-engine-driven cooling equipment with performance and price characteristics similar to the 15-ton rooftop units is made available in a range of sizes (2 to 2,000 tons) and configurations (chillers, split systems, package units), the aggregate potential NPV is over $\$ 100$

(a) Source energy is defined here as the energy input to the power plant in the case of electricity, or the energy input to the regional gas transmission system in the case of natural gas, to provide a given amount of energy at the customer's meter. By this definition, source energy includes transmission and distribution losses and generation losses, but does not include energy input required for fuel extraction, processing, and transportation to get the fuel to the region. 
million. Full federal-sector penetration of the technology would result in about $396,000 \mathrm{MWh} / \mathrm{yr}$ of electric energy use being displaced by $5,628,000 \mathrm{MBtu} / \mathrm{yr}$ of natural gas consumption. These numbers can be extrapolated to the entire stock of federally owned buildings if it is assumed that the distributions of building type, installed cooling capacity, climate, and utility rates for the entire federal sector are well represented by the 240 sites. For the entire federally owned building stock, the potential NPV and energy savings are about twice as large.

The analysis shows that replacing retired elecric-powered cooling equipment with gas-powered equipment is generally cost-effective in areas with high electric rates, moderate gas rates, and annual cooling loads that result in present value electric energy/operating costs that are at least twice the comparable electric unit's replacement cost minus any utility rebate. Annual operating cost is primarily a function of annual full load equivalent operating hours (cooling) and gas and electric rate structures.

For example, this technology was found to be cost effective at sites where marginal electricity cost (per MBtu at the meter) is more than four times the marginal gas cost (per MBtu at the meter) and annual full-load-equivalent (AFLE) cooling hours exceed 2,000. This rule-of-thumb was derived from the analysis of sites with marginal gas prices of $\$ 2.20$ to $\$ 7.30$ per MBtu. Applications with fewer AFLE cooling hours will be cost effective at correspondingly higher electric-to-gas price ratios. 


\section{Acknowledgments}

The authors wish to acknowledge the participation, review, comments, and support provided to this project by the CRADA participants and others associated with the project. These include $\mathrm{K}$. Dean DeVine (now retired), Federal Energy Management Program; Commander Mike Strand and Jim Edmond, NASWG; Bob Ellis, Trico Energy; Chuck Karr, Thermo King; Terry Falvey, Northern Division, NAVFAC; Jack Flanigan, Greg Byrd, Robert McNulty, and Jim Verna, PECO Energy; and Rich Sweetser, AGCC. 



\section{Contents}

Preface $\ldots \ldots \ldots \ldots \ldots \ldots \ldots \ldots \ldots \ldots \ldots \ldots \ldots \ldots \ldots \ldots \ldots \ldots \ldots$

Executive Summary $\ldots \ldots \ldots \ldots \ldots \ldots \ldots \ldots \ldots \ldots \ldots \ldots$

Acknowledgments $\ldots \ldots \ldots \ldots \ldots \ldots \ldots \ldots \ldots \ldots \ldots \ldots \ldots \ldots \ldots$

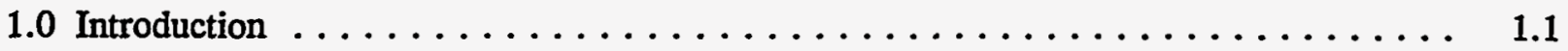

2.0 Background $\ldots \ldots \ldots \ldots \ldots \ldots \ldots \ldots \ldots \ldots \ldots \ldots \ldots \ldots \ldots \ldots \ldots \ldots \ldots$

2.1 Facility Description $\ldots \ldots \ldots \ldots \ldots \ldots \ldots \ldots \ldots \ldots \ldots \ldots \ldots \ldots \ldots$

2.2 Description of the Previous Rooftop Units . . . . . . . . . . . . 2.2

2.3 Description of Gas-Engine-Driven Rooftop Units $\ldots \ldots \ldots \ldots \ldots \ldots \ldots$

2.4 Analysis that Supported Gas for Cooling . . . . . . . . . . . . . 2.6

2.5 Technology Assessment Methodology $\ldots \ldots \ldots \ldots \ldots \ldots \ldots \ldots \ldots$

3.0 Field Performance Monitoring $\ldots \ldots \ldots \ldots \ldots \ldots \ldots \ldots \ldots \ldots \ldots \ldots \ldots$

3.1 Data Acquisition System $\ldots \ldots \ldots \ldots \ldots \ldots \ldots \ldots \ldots \ldots \ldots \ldots \ldots \ldots$

3.2 Measurements for Field Performance Evaluation . . . . . . . . . . 3.2

3.3 Acquired Data $\ldots \ldots \ldots \ldots \ldots \ldots \ldots \ldots \ldots \ldots \ldots \ldots \ldots \ldots \ldots$

4.0 Observed Performance and Operation $\ldots \ldots \ldots \ldots \ldots \ldots \ldots \ldots \ldots \ldots \ldots$

4.1 Cooling Loads $\ldots \ldots \ldots \ldots \ldots \ldots \ldots \ldots \ldots \ldots \ldots \ldots \ldots \ldots \ldots$

4.2 Cooling Efficiency $\ldots \ldots \ldots \ldots \ldots \ldots \ldots \ldots \ldots \ldots \ldots \ldots \ldots \ldots$

4.3 Cooling Operational Improvements $\ldots \ldots \ldots \ldots \ldots \ldots \ldots \ldots \ldots$

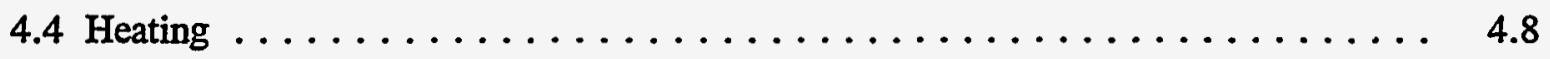

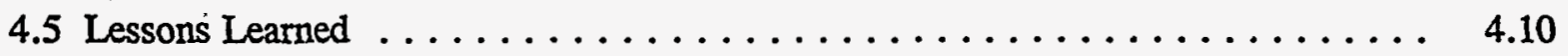


5.0 Annual Performance and Life-Cycle Cost $\ldots \ldots \ldots \ldots \ldots \ldots \ldots \ldots \ldots$

5.1 Base-Case Definition $\ldots \ldots \ldots \ldots \ldots \ldots \ldots \ldots \ldots \ldots \ldots \ldots \ldots \ldots \ldots$

5.2 Normal Year Loads $\ldots \ldots \ldots \ldots \ldots \ldots \ldots \ldots \ldots \ldots \ldots \ldots \ldots \ldots \ldots \ldots$

5.3 Operating Costs $\ldots \ldots \ldots \ldots \ldots \ldots \ldots \ldots \ldots \ldots \ldots \ldots \ldots \ldots \ldots \ldots \ldots$

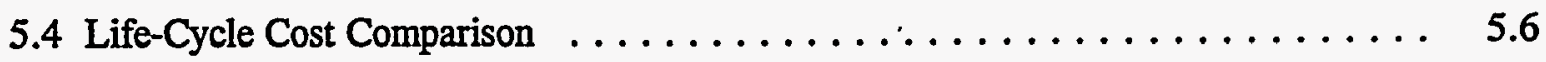

6.0 Conclusions and Recommendations $\ldots \ldots \ldots \ldots \ldots \ldots \ldots \ldots \ldots \ldots \ldots \ldots \ldots$

6.1 Savings Potential at NASWG $\ldots \ldots \ldots \ldots \ldots \ldots \ldots \ldots \ldots \ldots \ldots \ldots \ldots$

6.2 Savings Potential in the Federal Sector $\ldots \ldots \ldots \ldots \ldots \ldots \ldots \ldots \ldots \ldots$

6.3 Conditions for Implementation $\ldots \ldots \ldots \ldots \ldots \ldots \ldots \ldots \ldots \ldots \ldots \ldots \ldots$

7.0 References $\ldots \ldots \ldots \ldots \ldots \ldots \ldots \ldots \ldots \ldots \ldots \ldots \ldots \ldots \ldots \ldots \ldots \ldots$

Appendix A - Summary of Activity Leading to the Cooperative R\&D Agreement and the Joint Statement of Work . . . . . . . . . . . . . . . A.1

Appendix B - Glossary of Terms and Abbreviations $\ldots \ldots \ldots \ldots \ldots \ldots \ldots$ 


\section{Figures}

2.1 Floor Plan of Navy Exchange $\ldots \ldots \ldots \ldots \ldots \ldots \ldots \ldots \ldots \ldots \ldots \ldots \ldots \ldots \ldots$

2.2 Navy Exchange: View from the East $\ldots \ldots \ldots \ldots \ldots \ldots \ldots \ldots \ldots \ldots .2$

2.3 Navy Exchange: East Wall Detail $\ldots \ldots \ldots \ldots \ldots \ldots \ldots \ldots \ldots \ldots \ldots \ldots$

2.4 Cut-Away View of the Thermo King Equipment $\ldots \ldots \ldots \ldots \ldots \ldots \ldots \ldots 2.4$

2.5 Thermo King Unit 1: View from the South $\ldots \ldots \ldots \ldots \ldots \ldots \ldots \ldots \ldots$

3.1 Data Acquisition System $\ldots \ldots \ldots \ldots \ldots \ldots \ldots \ldots \ldots \ldots \ldots \ldots \ldots \ldots \ldots \ldots \ldots \ldots .2$

3.2 Location of Thermostat Controls in Relation to TK Units and Air Distribution Systems for the Retail Sales Area of $12,100 \mathrm{ft}^{2} \ldots \ldots \ldots \ldots \ldots .4$

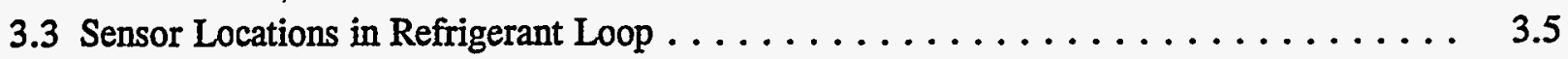

3.4 Sensor Locations in Zone and Air-Side Loop $\ldots \ldots \ldots \ldots \ldots \ldots \ldots \ldots \ldots$

4.1 Daily Average Fuel Input and Temperature in the 1992 Cooling Season . . . . . . . 4.2

4.2 Daily Average Fuel Input and Temperature in the 1993 Cooling Season . . . . . . . 4.2

4.3 Relation Between Cooling-Mode Fuel Use and Mean Daily Temperature . . . . . . 4.3

4.4 Average Daily COP by Cooling Stage Measured in $1992 \ldots \ldots \ldots \ldots \ldots \ldots .4$

4.5 1992 Measured COPs of Unit 1 Versus Manufacturer's COP Ratings $\ldots \ldots \ldots \ldots .4$

4.6 Unit 1 Measured Part-Load Operating Times Versus Those Used by the ARI Standard to Compute Seasonal COP . . . . . . . . . . . . . . . 4.5

4.7 Average Day Load Profiles in the Cooling Season $\ldots \ldots \ldots \ldots \ldots \ldots \ldots .6$

4.8 Average Day Fan Energy Use in the Cooling Season $\ldots \ldots \ldots \ldots \ldots \ldots \ldots .7$

4.9 Reduction in Daily Cooling Load that Resulted from Economizer Operation . . . . . . 4.7

4.10 Relations Between Daily Fuel Used for Heating and Mean Daily Temperature . . . . . 4.9

4.11 Average Day Fan Energy Use Profiles in the Heating Season $\ldots \ldots \ldots \ldots \ldots .9$

4.12 Average Day Fuel Use Profiles in the Heating Season $\ldots \ldots \ldots \ldots \ldots \ldots . . \ldots$ 
5.1 Comparison of Normal-Year and 1992 Ambient Temperature Distributions $\ldots \ldots . \ldots$

5.2 Energy Requirements for Electric and Natural Gas Alternatives $\ldots \ldots \ldots \ldots \ldots \ldots$

5.3 Monthly Energy Costs for Electric and Natural Gas Alternatives . . . . . . . . . 5.5

5.4 Distribution of Monthly Energy Costs for the Electric Alternative $\ldots \ldots \ldots$

6.1 LCC Effectiveness Thresholds for the Gas-Cooling Technology Based on the REEP Data for 240 Military Sites . . . . . . . . . . . . . . . . 6.5 


\section{Tables}

2.1 Capacity and Related Operating Parameters $\ldots \ldots \ldots \ldots \ldots \ldots \ldots$

2.2 Life-Cycle Cost of HVAC Options Considered for the NEX in $1990 \ldots \ldots \ldots \ldots$

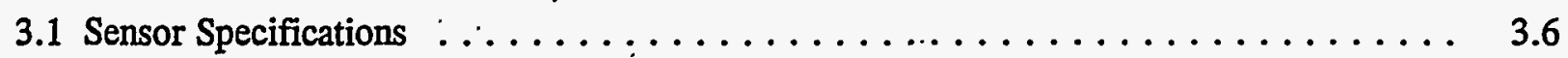

5.1 Available Climate Data $\ldots \ldots \ldots \ldots \ldots \ldots \ldots \ldots \ldots \ldots \ldots \ldots \ldots \ldots \ldots$

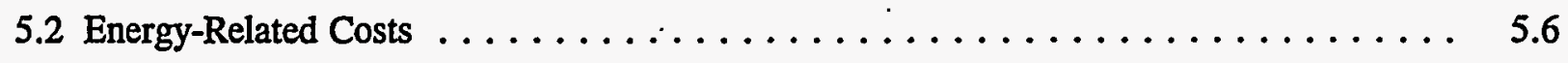

5.3 Comparison of Present-Value Costs $\ldots \ldots \ldots \ldots \ldots \ldots \ldots \ldots \ldots \ldots \ldots \ldots$ 


\subsection{Introduction}

The purpose of the New Technology Demonstration Program (formerly the Test Bed Demon- stration Program) is to accelerate the deployment of advanced energy technologies through government and private-sector partnerships that install and evaluate technology performance in the federal sector. Through the results of a new technology demonstration, federal agency decision makers have more "hands on" information with which to validate a decision to utilize that technology in their facilities. Energy saving technologies emerge regularly in the marketplace. This program seeks to identify those technologies, determine which have the broadest application for the federal sector, and then shorten the deployment time for those that prove beneficial to the federal market.

Beginning in 1989 , activities were initiated to develop a demonstration program that could facilitate the introduction of new technologies into the federal sector. The first major program activity was to develop the overall concept and description of the program. Four concurrent activities were then undertaken, including development of the criteria for interagency and cooperative agreements. Another of those concurrent activities was to identify candidate technologies for test bed demonstrations. This was done through a series of meetings with government and industry representatives. A number of technologies were originally suggested and the scope of these options was narrowed through these discussions. Specific criteria associated with energy, cost, and environmental challenges in the federal sector were also identified.

Based on discussions and meetings with Department of Defense (DoD) officials, five technology alternatives were identified and ranked. The technology receiving the highest ranking was natural-gasengine-driven chillers. The reasons for this decision were the clean air aspects of the technology; potential energy savings; and potential cost savings. No limitation on equipment size was specified. Through selection of a target technology the groundwork for the first (pilot) new technology demonstration project was complete.

A solicitation of interested parties to participate in this first test bed demonstration project was. made available in mid-1991 to utilities and manufacturers. The solicitation explained the purposes of the program and highlighted the benefits to be derived from such a public- and private-sector partnership. A search was undertaken to identify a federal site that was within the service area of the responding utilities, had a facility infrastructure that was broadly representative of the federal sector, and a building that was appropriate for the technology.

In early 1992, during the course of the search, the interest of some utilities and manufacturers changed and they could no longer consider participation. This left three manufacturers and three utilities still interested in participating in the first test demonstration. PECO Energy identified a federal site that had installed equipment from one of the three manufacturers that remained interested. The other two utilities also identified candidate sites, but these were found unsatisfactory. One was a postal facility where the private-sector building owner did not feel the subject equipment size was appropriate for the building. The other, a presidential library, would not have been ready for test initiation by the 
summer of 1992. Another possibility in Philadelphia was considered but found unsuitable due to the historic nature of the subject structure and its inability to accommodate the equipment. Although additional search efforts could have been undertaken to identify another federal site, the site proposed by PECO Energy was determined to be most appropriate to serve as the first project under the New Technology Demonstration Program. This decision was driven in large part by time, considering the desire to have the equipment installed and operational for evaluation during the summer of 1992 .

The site selected for the first FEMP test bed demonstration was the Naval Air Station in Willow Grove (NASWG), Pennsylvania. The building selected for application of the gas-engine-driven airconditioning technology was a retail facility known to its customers as the Navy Exchange (NEX). The equipment installed was Thermo King (TK) natural-gas-engine-driven rooftop heating and air-conditioning equipment as submitted by Thermo King in their response to the solicitation. Two 15-ton units were installed on the roof to supply the heating and cooling to approximately $12,500 \mathrm{ft}^{2}$ of the $16,000 \mathrm{ft}^{2}$ structure. These units. were already installed in the building, ${ }^{(a)}$ having been the first such sales in the federal sector. Other organizations responding to the solicitation and participating in the project were PECO Energy and the American Gas Cooling Center. Together with DOE these organizations were interested in forming a partnership to determine how the equipment would perform in the federal sector.

These organizations were contacted and a draft Cooperative Research and Development Agreement (CRADA) and Joint Statement of Work (JSOW) were prepared for consideration by each of the parties. The CRADA and JSOW documents formalize the partnership by which each organization would jointly sponsor and participate in the monitoring and evaluation of the performance of the Thermo King equipment. After review, comment, and negotiation these documents were finalized. A key concept and portion of these documents addresses the in-kind services which each organization brought to the project. Rather than DOE supporting the entire project, each organization supported certain specific project activities. This resulted in the cost and value of the project being shared by DOE and the other four participants.

The purpose of the demonstration project at Willow Grove is to evaluate the performance and economics of natural-gas-engine-driven ${ }^{(b)}$ rooftop air-conditioning equipment within the federal sector. Included in the evaluation is energy use and cost, operation and maintenance, reliability, and building

(a) The existing equipment, installed in 1983, used electricity for cooling and fuel oil for heating. The facility engineer initiated a project to explore replacement alternatives because of the high cost to operate and maintain the equipment.

(b) The terms "gas-powered" and "gas-engine-driven" are used interchangeably in this report to refer the TK air-conditioning units. Note, however, that "gas powered" cooling equipment generally includes a variety of technologies, including gas-fired absorption machines and gas-fired desiccant cooling technologies. 
comfort. With this information the benefits of the equipment have been identified and communicated to others in the federal sector. As delineated in this final report, $\$ 13,000$ in energy costs will be saved during a normal (weather) year at NASWG.

The primary tasks in the NASWG demonstration included planning, data acquisition system design and installation, data acquisition and analysis, and reporting of results. The planning activity was led by PNL and NASWG. This included all activities necessary to define the project and the methodology by which the equipment would be evaluated. Considerable support for this activity came from PECO Energy and the AGCC who contracted with the AGAL to provide the data acquisition system. The data acquisition system (DAS) was installed by AGAL with additional measurements recommended by PNL. NASWG staff assisted with the DAS installation and PECO Energy provided the necessary gas metering devices.

Beginning in early June 1992 operating data were logged by the DAS every 15 minutes and downloaded daily to computer systems at PNL for classification and analysis. Concurrent with the initiation of data acquisition, a media presentation was conducted at Willow Grove and the activities to be conducted during the test period presented to the press. The final results of the test, which are the subject of this report, were determined in early 1994. The interim results of the test were reported in PNL-8677 (Armstrong and Conover 1993). During the test period, and under the terms of the CRADA, Thermo King provided service and maintenance at no cost to NASWG. The results of the first summer of operation were presented at a workshop for federal facility managers and energy and procurement officials on December 11, 1992, in Washington, D.C. This outreach activity was sponsored by the AGCC as part of their project support.

The purpose of this report is to present the information gathered during the entire testing period at NASWG. Background on the facility and the project is provided in Section 2.0. The manner in which the equipment was monitored in the field is presented in Section 3.0, and Section 4.0 presents the observations and analysis results for the monitoring period. Normal year performance is estimated from the measured performance results in Section 5.0 and a life-cycle cost analysis is presented. Section 6.0 provides the conclusions and recommendations derived from the activity at NASWG. References are included in Section 7.0. Appendix A summarizes the CRADA and joint statement of work development histories. Terms and abbreviations are defined in Appendix B. 


\subsection{Background}

The building selected for the inaugural testing/demonstration under the NTDP had recently installed the new equipment and was just being readied for its first cooling season since the retrofit. This installation was the first application of the TK gas-engine-driven cooling technology in the federal sector.

\subsection{Facility Description}

The Navy Exchange (NEX) at NASWG is a 15,277 $\mathrm{ft}^{2}$ single-story masonry structure built in 1982 . The retail sales area, covering $12,500 \mathrm{ft}^{2}$, was previously heated and cooled by two conventional rooftop units (RTUs) using \#2 fuel oil as the heating fuel and direct expansion refrigeration with electrically driven reciprocating compressors for cooling. The aggregate capacity of these units was 225,000 Btuh heating and 380,000 Btuh cooling. The storage area, covering 3,200 $\mathrm{ft}^{2}$ (with an additional 3,000 $\mathrm{ft}^{2}$ mezzanine above), was heated by $\# 2$ fuel oil fired unit heaters and was not cooled. The snack shop, covering $210 \mathrm{ft}^{2}$, was cooled and heated by a split direct expansion (DX) system of 17,000 Btuh nominal cooling capacity with electric resistance heaters of $3 \mathrm{~kW}$ capacity. Figure 2.1 provides a layout of the structure, and Figure 2.2 depicts the NEX from a distance with the two TK units just visible on the roof.

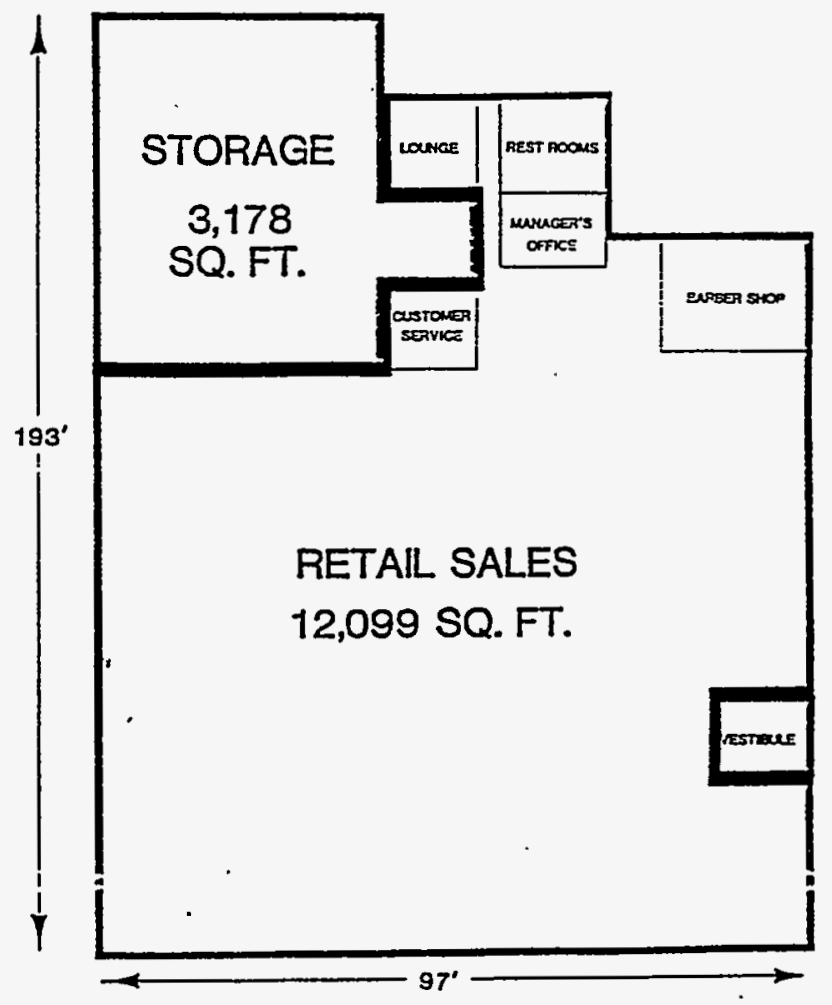

Figure 2.1. Floor Plan of Navy Exchange 


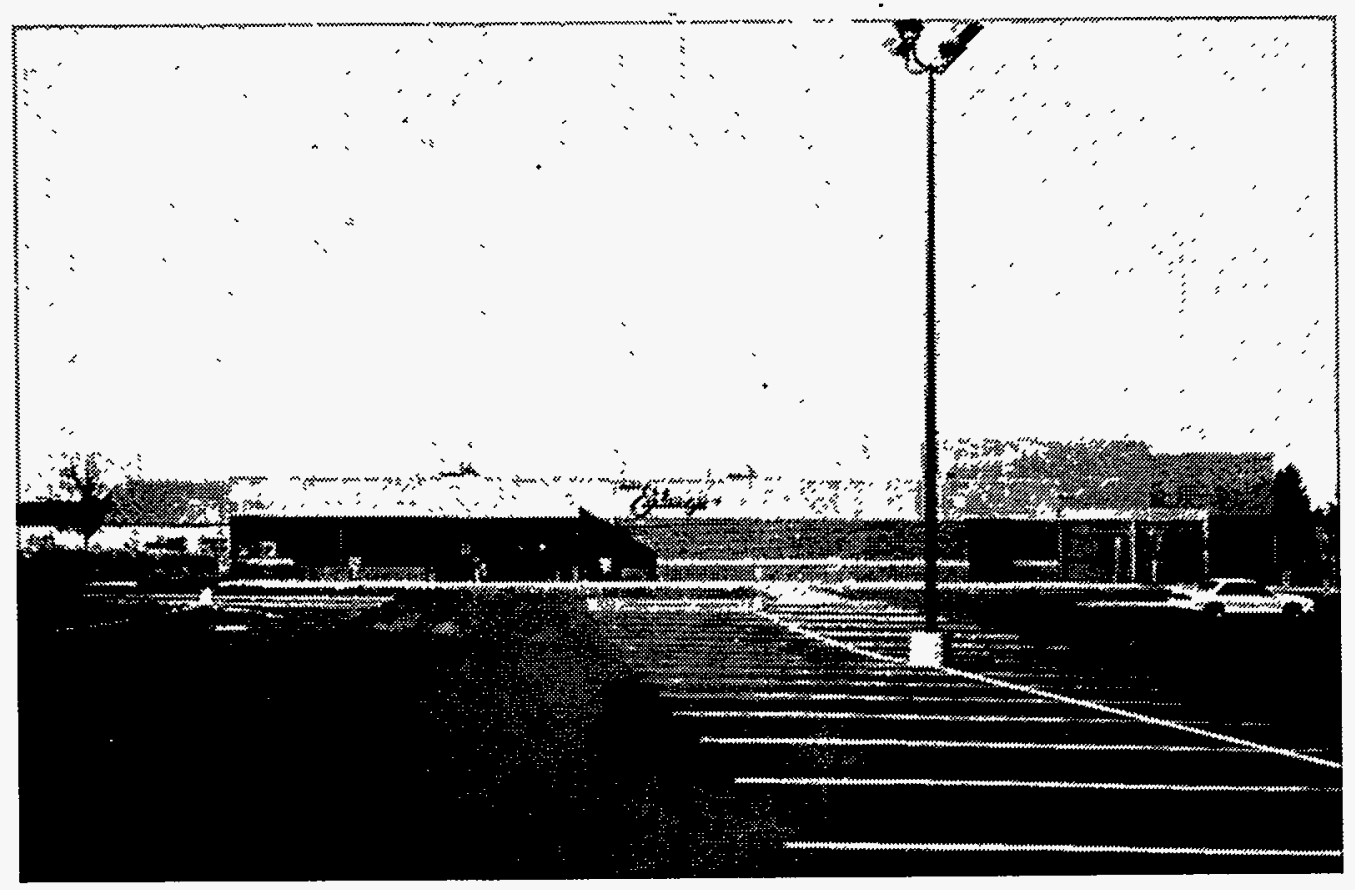

Figure 2.2. Navy Exchange: View from the East

The structure is uninsulated with concrete " $T$ " walls and roof. The exterior wall finish is white and the roof is black (tar and pea gravel). A small portion of the front (east facing) wall, as shown in Figure 2.3, consists of display windows. The rest of the walls are windowless.

The NEX is occupied from 0700 to 1700 Tuesday through Friday, 0800 to 1600 Saturday and Sunday; it is closed on Monday. The average number of occupants is estimated to be 10 and the peak (daily) number is estimated to be 35 . Lighting is provided by fluorescent fixtures for $98 \%$ of the floor area with the balance covered by incandescent and high pressure sodium fixtures.

\subsection{Description of the Previous Rooftop Units}

No data are available on the performance of the conventional rooftop units that were used prior to 1992 nor on their electrical consumption. However, the main purpose of this particular project is to compare current state-of-the-art conventional technology (energy efficient electric rooftop unit) with a current state-of-the-art alternative technology (gas-engine-driven rooftop unit). This is because selection of a replacement technology should be based on a comparison of currently available candidate technologies. Information on the field performance or nominal performance of the 10 -year-old units could be used as a "reality check" but is not directly relevant to the comparative analysis. The field performance that would be realized using state-of-the-art conventional technology is addressed in Section 5.1, "Base-Case Definition." 


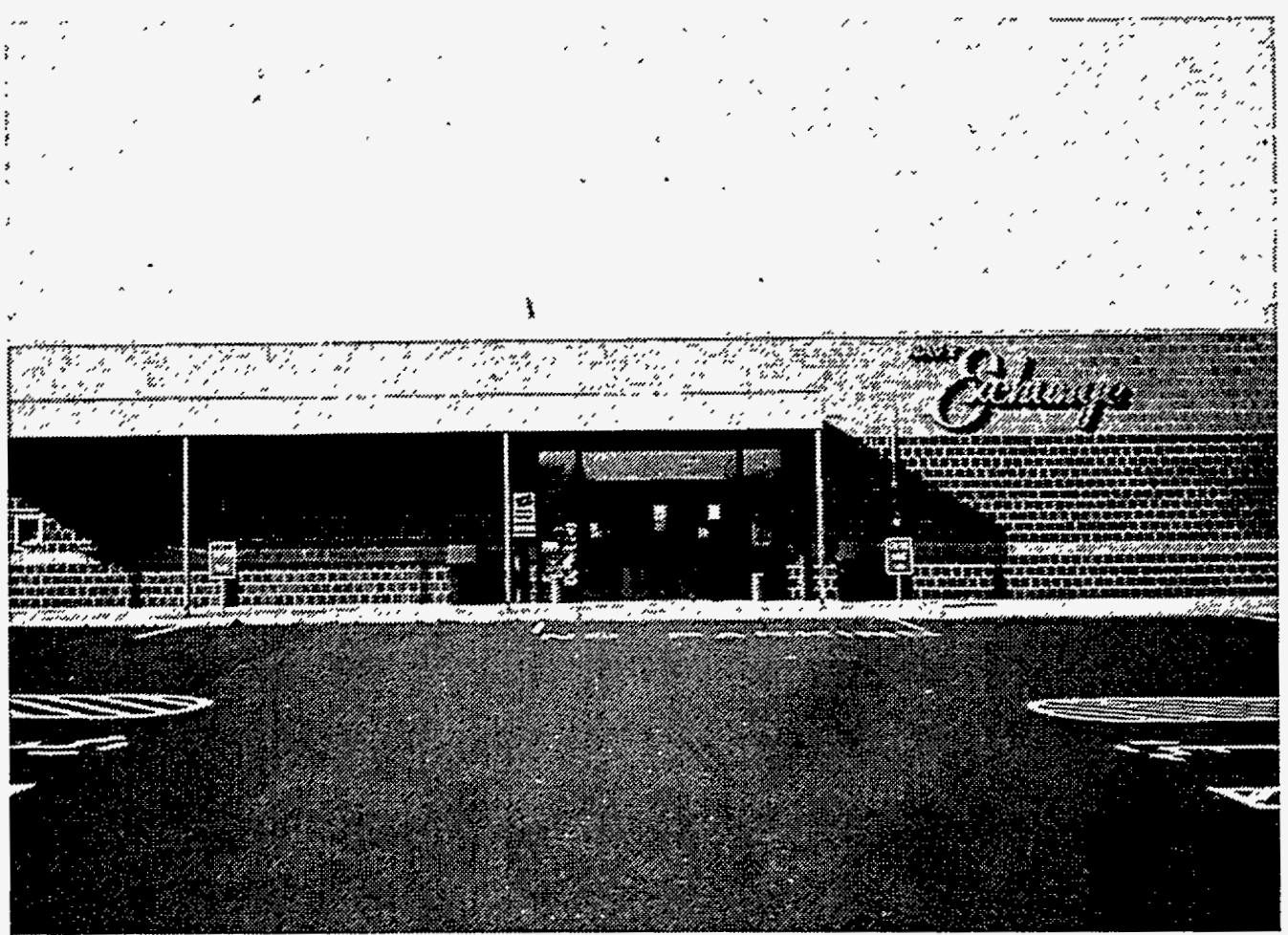

Figure 2.3. Navy Exchange: East Wall Detail

\subsection{Description of Gas-Engine-Driven Rooftop Units}

The existing rooftop units were replaced in early 1992 by new units manufactured by TK. The two TK units are identical even though the units they replaced were of different sizes. The new technology is designed as a direct replacement for conventional single-zone, gas-heating, electric-cooling rooftop units. Each unit is factory assembled, charged with R-22 (an HCFC refrigerant), and requires singlepoint connections of electrical power (for the supply air fan motor) and natural gas. Maximum cooling capacity is 190,000 Btuh at ARI Standard 360 (ANSI/ARI 1986) rating conditions. Maximum heating capacity is 216,000 Btuh. A cutaway view of the unit, showing the main mechanical components, appears in Figure 2.4. 


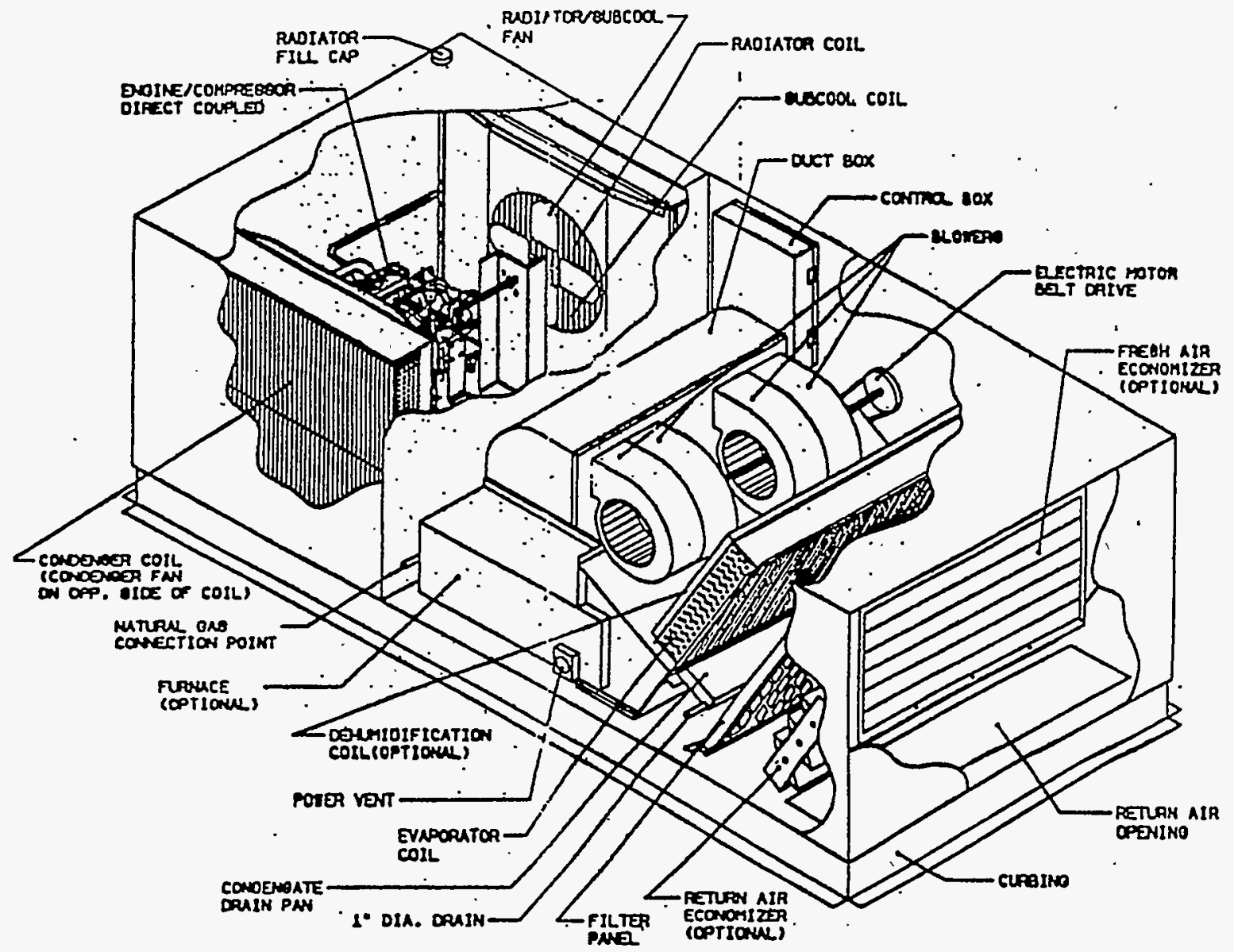

Figure 2.4. Cut-Away View of the Thermo King Equipment

Variable engine speed allows for cooling operation in three stages, and cylinder unloading provides an additional stage for light load conditions as indicated in Table 2.1.

Table 2.1. Capacity and Related Operating Parameters

\begin{tabular}{|c|c|c|c|c|c|}
\hline Stage & Mode & $\begin{array}{c}\text { Capacity } \\
\text { (kBtu/h) }\end{array}$ & $\begin{array}{c}\text { Engine Speed } \\
\text { (rpm) }\end{array}$ & \multicolumn{2}{|c|}{$\begin{array}{c}\text { Supply Air Fan } \\
\text { (rpm) }\end{array}$} \\
\hline H1 & Heating & 108 & n.a. & 860 & 1 \\
H2 & Heating & 216 & n.a. & 1760 & 5 \\
\hline C1 & Cooling & 28 & $1000^{(\text {(a) }}$ & 860 & 1 \\
C2 & Cooling & 84 & 1000 & 1760 & 5 \\
C3 & Cooling & 143 & 1500 & 1760 & 5 \\
C4 & Cooling & 190 & 2400 & 1760. & 5 \\
\hline (a) Fan power depends on distribution system flow-pressure characteristic. The nominal values for the standard motor are shown. \\
(b) With two of four compressor cylinders unloaded. The units installed at NASWG are equipped with the standard motor. \\
\hline
\end{tabular}


Characteristics of the unit's major components are described below.

Condenser. A 5-row coil with a face area of $15 \mathrm{ft}^{2}$, tube diameter of $3 / 8 \mathrm{in}$., and fin spacing of 12 per inch is provided to reject heat from the condensing refrigerant. The engine driven condenser fan is 24 inches in diameter and provides $9000 \mathrm{cfm}$ of air flow with the engine running at $2400 \mathrm{rpm}$.

Evaporator. The 6-row evaporator coil has a face area of $13 \mathrm{ft}^{2}$, tube diameter of $3 / 8 \mathrm{in}$., and fin spacing of 9 per inch. A 3-ton expansion valve is provided for the upper (75\%) section of the evaporator and a 3-ton expansion valve is provided for the lower (25\%) section of the evaporator. Both are external equalizer type with a superheat setting of $20 \pm 5^{\circ} \mathrm{F}$.

Compressor. The 4-cylinder V-configuration compressor displaces $30 \mathrm{in}^{3}$, and cylinder unloading is provided on two cylinders. The unit holds a charge of approximately $30 \mathrm{lbm}$ of R-22 (an HCFC refrigerant).

Engine. A 4-cylinder in-line engine displacing 163 in $^{3}$ produces $40 \mathrm{hp}$ at $2400 \mathrm{rpm}$. An 18-inchdiameter fan provides $4000 \mathrm{~cm}$ through the radiator at $2400 \mathrm{mpm}$ engine speed and the refrigerant subcooler rejects heat to this airstream.

Supply Fan. Two centrifugal blowers on a common, belt-driven shaft provide nominal supply airflow rates of $6000 \mathrm{cfm}$ at full speed and $3000 \mathrm{cfm}$ at half speed. A 208-volt, 3-phase, 5-hp twospeed $(1720 / 860 \mathrm{rpm})$ motor with an adjustable drive sheave powers the blowers. Table 1 gives the supply fan motor speed for each heating and cooling stage. The air-side design is typical of small to medium sized rooftop units in not incorporating a return fan or an exhaust air path.

Economizer. A single actuator motor operates a pair of opposed blade dampers in the return air and outside air streams; this subsystem allows modulation of the outside air fraction from 0 to $100 \%$. Economizer operation is controlled by the thermostat based on outdoor and return air temperatures. (Later models use differential enthalpy control.)

Maintenance. The rooftop unit requires biannual preventive maintenance which includes coil cleaning and supply fan and damper maintenance identical to the maintenance required for the conventional technology. Maintenance peculiar to the gas-engine-driven technology includes engine winterization at the end of each cooling season and an oil change every spring. Replacement or refacing of valves, seats, and guides is recommended by the manufacturer at 10,000-operating-hour intervals, and engine rebuilding is recommended at 20,000-operating-hour intervals. These rebuild intervals appear to be realistic based on natural-gas-fueled engine operating experiences of others (Mathews 1992).

Thermostat., A Honeywell T7400 programmable microprocessor-based thermostat is used to control the two heating and four cooling stages, the economizer, and night setback and temperature recovery operation of each unit. The thermostat uses proportional-plus-integral control to determine the required heating or cooling stage and the cycling rate that will minimize deviations from the setpoint. 
The room temperature sensor can be internal or external, and multiple sensors can be used to provide a spatial average room temperature. The thermostat also provides intelligent outside air control and ramped setpoint recovery.

One of the two TK rooftop units (Unit 1) installed at NASWG is pictured in Figure 2.5. The engine, compressor, and condenser are located in the left-hand end of the unit. Louvered doors on the left end are open for service. Condenser and engine radiator air enter through and from below the left end. The burners, heat exchanger, induced-draft fan, and unit controls are located in the center section. Combustion air intake louvers are visible on the burner service access panel. A removable panel on the opposite side of the center section provides access to the controls. The supply-air fan, evaporator coil, and economizer dampers are located in the right-hand section of the unit. Service access is from the opposite side. The outside air intake hood is visible on the right end of the unit.

The roof curb supports the center and right-hand sections of the unit. The return air duct connects to the bottom of the right-hand section. The supply-air duct connects under the center section.

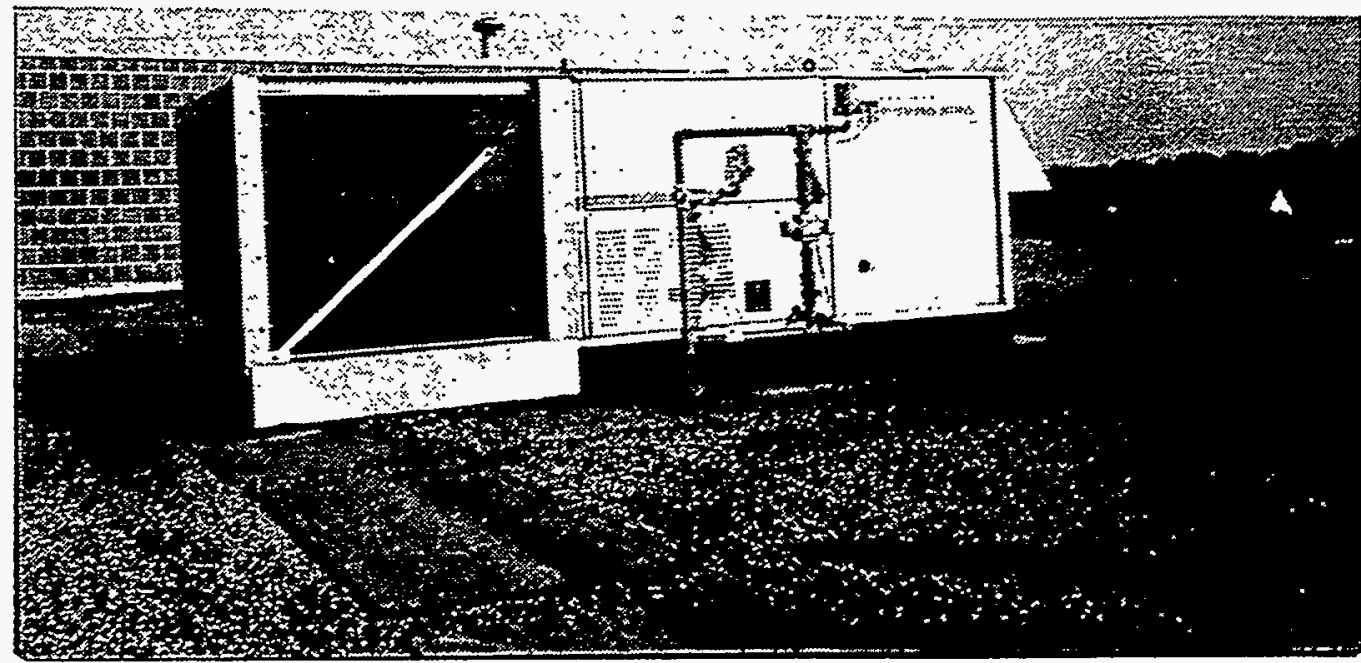

Figure 2.5. Thermo King Unit 1: View from the South

\subsection{Analysis that Supported Gas for Cooling}

The decision to replace the existing rooftop units with gas-engine-driven rooftop units was based on a life-cycle cost (LCC) analysis of five different HVAC plant options (Falvey 1990). These options are listed in Table 2.2 along with the option of replacing the worn-out existing RTUs with current conven- 
tional technology (essentially identical) RTUs. The lowest LCC option was replacement with naturalgas-engine-driven RTUs. ${ }^{(a)}$

Table 2.2. Life-Cycle Cost of HVAC Options Considered for the NEX in 1990

\begin{tabular}{|l|c|c|c|}
\hline \multicolumn{1}{|c|}{ Option } & $\begin{array}{c}\text { Initial } \\
\text { Cost }\end{array}$ & $\begin{array}{c}\text { Annualized } \\
\text { Operating Cost }\end{array}$ & $\begin{array}{c}\text { Life-Cycle } \\
\text { Cost }\end{array}$ \\
\hline Similar RTUs and unit heaters & $\$ 51,330$ & $\$ 14,682$ & $\$ 154,450$ \\
\hline $\begin{array}{l}\text { Heat by Steam from Central Plant and } \\
\text { Cool by Electric Chillers }\end{array}$ & $\$ 96,369$ & $\$ 16,273$ & $\$ 210,644$ \\
\hline $\begin{array}{l}\text { Heat by Steam from Central Plant and } \\
\text { Cool by Gas Chillers }\end{array}$ & $\$ 107,705$ & $\$ 8,019$ & $\$ 176,109$ \\
\hline Co-generation with Absorption Chillers & $\$ 189,419$ & $\$ 3,657$ & $\$ 215,104$ \\
\hline Double-effect Absorption Chiller/Heaters & $\$ 92,119$ & $\$ 7,875$ & $\$ 159,294$ \\
\hline Natural-Gas-fired RTUs & $\$ 77,972$ & $\$ 6,148$ & $\$ 130,416$ \\
\hline
\end{tabular}

\subsection{Technology Assessment Methodology}

The overall approach of the project was to measure field performance of the TK 15-ton natural-gasengine-driven rooftop air-conditioning equipment, extrapolate the data to normal weather year conditions, and compare to normal year performance of current conventional technology on both an energy and life-cycle cost basis.

To measure field performance, the units were instrumented and a data acquisition system and phone line for remote data upload were installed as described in Section 3.0.

To assess performance, the average COP in each of four cooling stages was determined from measured air-side temperature and humidity differences and fuel input rates as described in Sections 4.1 through 4.3 .

To extrapolate performance to normal weather year conditions, a cooling degree-day base temperature was determined from the correlation between measured daily cooling plant input energy and daily mean temperature. Normal year energy use was taken to be the product of energy use during the monitoring period and the ratio of normal-year cooling degree-days (CDD) to CDD experienced during the monitoring period.

(a) Note that the natural gas-fired RTUs have the lowest life-cycle cost even though the annual operating cost estimate is conservatively high. 
To estimate normal weather year performance of the current conventional technology, the hypothetical energy consumption during the monitoring period that would have resulted if the engine was replaced by an energy efficient motor was estimated. Normal weather year energy use was then taken to be the product of energy use during the monitoring period and the ratio of normal-year CDD to CDD experienced during the monitoring period. Normal year weather and performance estimates are developed in Sections 5.1 through 5.3.

To compare life-cycle costs, the FEMP/NIST life-cycle cost program (NIST 1986) and fuel escalation data (NIST 1992) were used as described in Section 5.4. The Code of Federal Regulations (10 CFR Part 465) requires that all energy improvements be justified by comparing the life-cycle costs of all reasonable alternatives. 


\subsection{Field Performance Monitoring}

Effective assessment of the performance of the TK units involved monitoring numerous operating characteristics of the equipment, building, and exterior environment. This necessitated the design and installation of a data acquisition system and the collection of operating data.

\subsection{Data Acquisition System}

Two data loggers were installed to monitor the performance of the two TK units. The Campbell Scientific CR10 is the basic unit of both loggers, but the logger for TK Unit 1 has a high-resolution analog extension module that provides additional analog channel capacity for thermocouples, thermopiles, resistance temperature detectors (RTD), and other low-level inputs. The capabilities of the data logger that are germane to this particular new technology demonstration are summarized below.

The logger has six differential analog input channels, any of which can be configured as two singleended channels. The analog extension module provides an additional 32 differential input channels. The basic accuracy of the logger is $0.2 \%$ of full-scale range (FSR) when operated between $-25^{\circ} \mathrm{C}$ and $+50^{\circ} \mathrm{C}$. Sampling takes $2.6 \mathrm{~ms}$ per channel in fast single-ended mode, $3.2 \mathrm{~ms}$ in fast differential mode, $8.6 \mathrm{~ms}$ in fast differential thermocouple mode, and $25.9 \mathrm{~ms}$ in $60 \mathrm{~Hz}$ rejection $(70 \mathrm{~dB})$ differential mode. Each channel can be configured to one of five input ranges: $\pm 2500 \mathrm{mV}, \pm 250 \mathrm{mV}$, $\pm 25 \mathrm{mV}$, and $\pm 7.5 \mathrm{mV}$. The analog input resistance is $20 \times 10^{10} \mathrm{ohm}$. The logger has eight status inputs and two eight-bit, $2000 \mathrm{~Hz}$ pulse inputs. The clock is accurate to \pm 1 minute per month.

The logger and instrumentation specifications and the data logging programs were developed by AGAL and were used for monitoring similar TK units in previous field monitoring work. The loggers for the NASWG installation were installed by AGAL on behalf of PECO Energy and AGCC. Transducers for measuring outside and room air conditions, engine fuel and supply fan power inputs, and refrigerant-side conditions and heat transfer rates were also installed by AGAL. Air-side instrumentation, added by PNL to TK Unit 1, included thermopiles to measure supply-return air temperature difference, outside-return air temperature difference, and outside-mixed air temperature difference, and a tipping bucket gauge to measure condensate flow rate at the drain of the evaporator coil. The loggers were programmed by AGAL to scan the PNL-added instrumentation as well as the original AGAL instrumentation.

Each logger communicates remotely via an RS-232 serial port, a modem, and a dedicated phone line. Polling stations were set up at AGAL, NASWG and PNL with PNL being the primary site for uploading and archiving the data. The PNL polling was performed nightly by a PC running a batch program that calls executable programs for uploading data from the NASWG CR10 loggers (and two other types of loggers used in other projects) in a predetermined sequence.

Figure 3.1 shows the data acquisition system installed on the north side of Unit 1. 


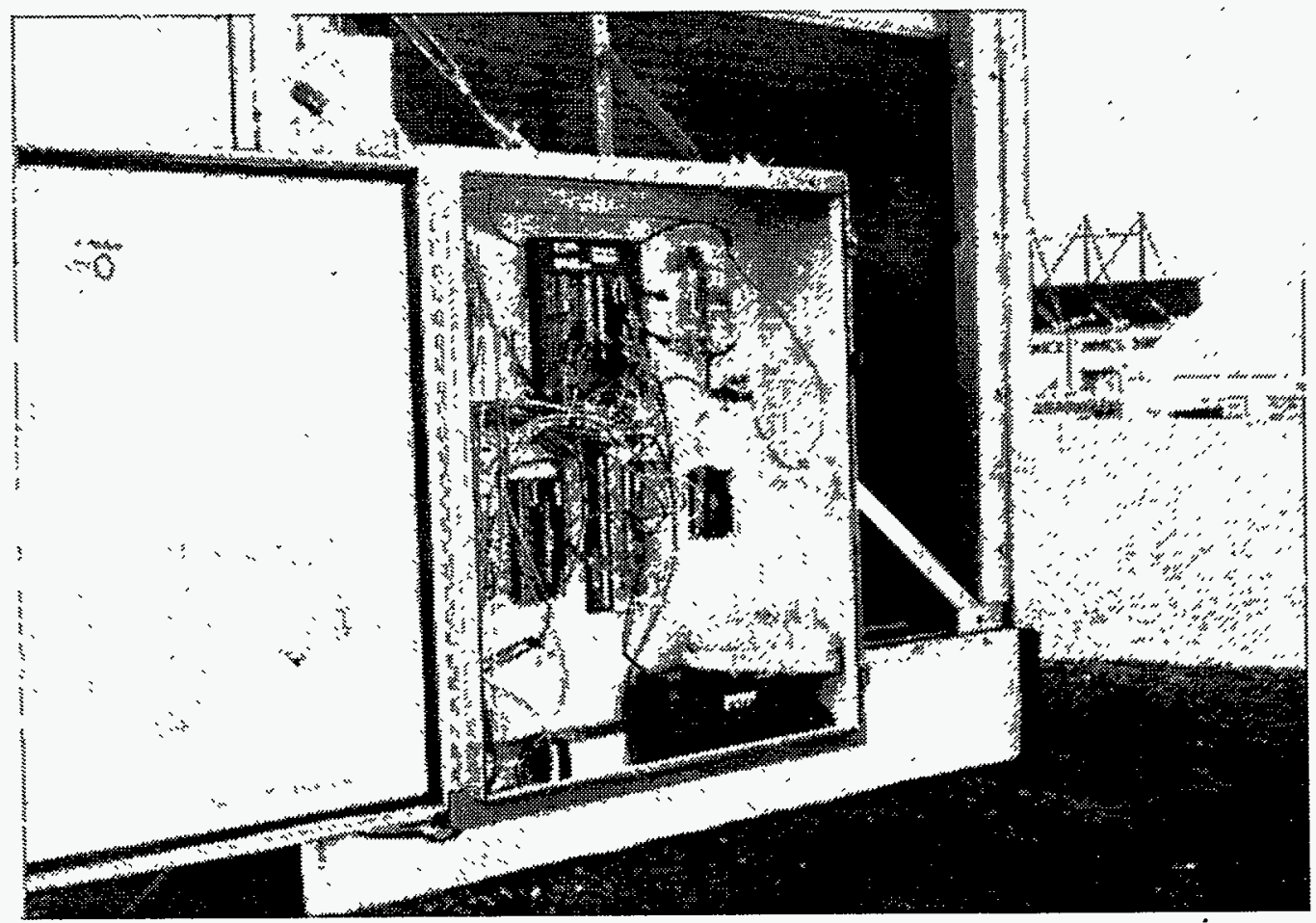

Figure 3.1. Data Acquisition System

\subsection{Measurements for Field Performance Evaluation}

Most of the measurements are used to evaluate performance (e.g., efficiency as a function of conditions) and to diagnose operational problems with the system being monitored. Additional sensors provide redundant measures of performance and monitoring system diagnostics. In the case of the gas powered rooftop air-conditioning units monitored at NASWG, the measurements can also be organized in terms of the units' major subsystems: engine, refrigerant circuit, air circuit, controls, and conditioned building space.

Engine/Compressor. The monitored conditions that affect engine performance are barometric pressure and ambient temperature and humidity. Outside air temperature and relative humidity sensors are located on the BX roof at the southeast corner of Unit 1. The engine performance is not measured directly, but the flow of natural gas to the engine is measured to assess the aggregate engine/ compressor performance. Compressor output is measured in terms of refrigerant mass flow rate and the pressures and temperatures of the refrigerant at the compressor's inlet and exhaust ports. Diagnostic points include manifold pressure, exhaust temperature and engine speed (RPM). 
Refrigerant Loop. The cooling effect is measured on the refrigerant and air sides of the evaporator coil. Refrigerant heat rates involve sensible heating and cooling of the refrigerant in its liquid and vapor states as well as latent heat transfer associated with refrigerant boiling and condensation. The refrigerant mass flow rate is measured downstream of the condenser where the refrigerant is normally in a liquid state. The latent heat picked up by the refrigerant is determined from the evaporator pressure and the sensible heat from the temperature of the leaving refrigerant minus the saturation temperature. The latter is a function of evaporator pressure. The latent heat rejected by the refrigerant is determined from the condenser pressure and the sensible heat from the superheating and subcooling temperatures measured, respectively, at the desuperheater inlet and the condenser outlet.

Air-Side Measurements. A redundant measure of the cooling effect is obtained on the air side of the evaporator coil. The latent load is inferred from the flow of water, which condenses on the cold air-side surfaces of the coil, as it drains from the condensate pan through a tipping-bucket gauge. The sensible load is determined from the change in air temperature; the change is measured by a sixjunction-pair thermopile connected between the mixed air and supply air plenums of the unit. The outside air fraction is determined from the outside air, return air, and mixed air temperatures. The mixed air humidity is determined from the outside air humidity, return air humidity and outside air fraction. The mixed air conditions are needed to develop a weather and load-normalization model that can be used to extrapolate the unit's monitored performance to a standard cooling season. One-time air flow measurements were made at each of the two supply fan speeds by a hot-wire anemometer. Each measurement was based on the average of 30. traverse points evenly distributed across the upstream face of the evaporator coil with the unit.in fan-only (no cooling) mode of operation. Four replications were made of each air flow measurement.

Conditioned Zone. The air temperature and humidity in the conditioned zone are measured in the vicinity of the two thermostats that control the two rooftop units. The locations of these thermostats in relation to the TK units and supply and return air points are shown in Figure 3.2.

Controls. The control signals for cooling stages 1 through 4 and heating stages 1 and 2 are monitored to provide a means of disaggregating the measured performance and conditions by mode of operation.

The sensor locations in relation to the mechanical subsystems of the rooftop unit are shown schematically in Figures 3.3 and 3.4. Sensor specifications are listed in Table 3.1.

\subsection{Acquired Data}

During the course of the 1992 and 1993 cooling and heating seasons, a considerable body of performance data were compiled. Service and maintenance data were gathered as well as the electronically recorded time-series data used to characterize equipment performance and operating conditions. The results of the analysis of the data and what they convey about equipment performance are presented in Section 4.0. 


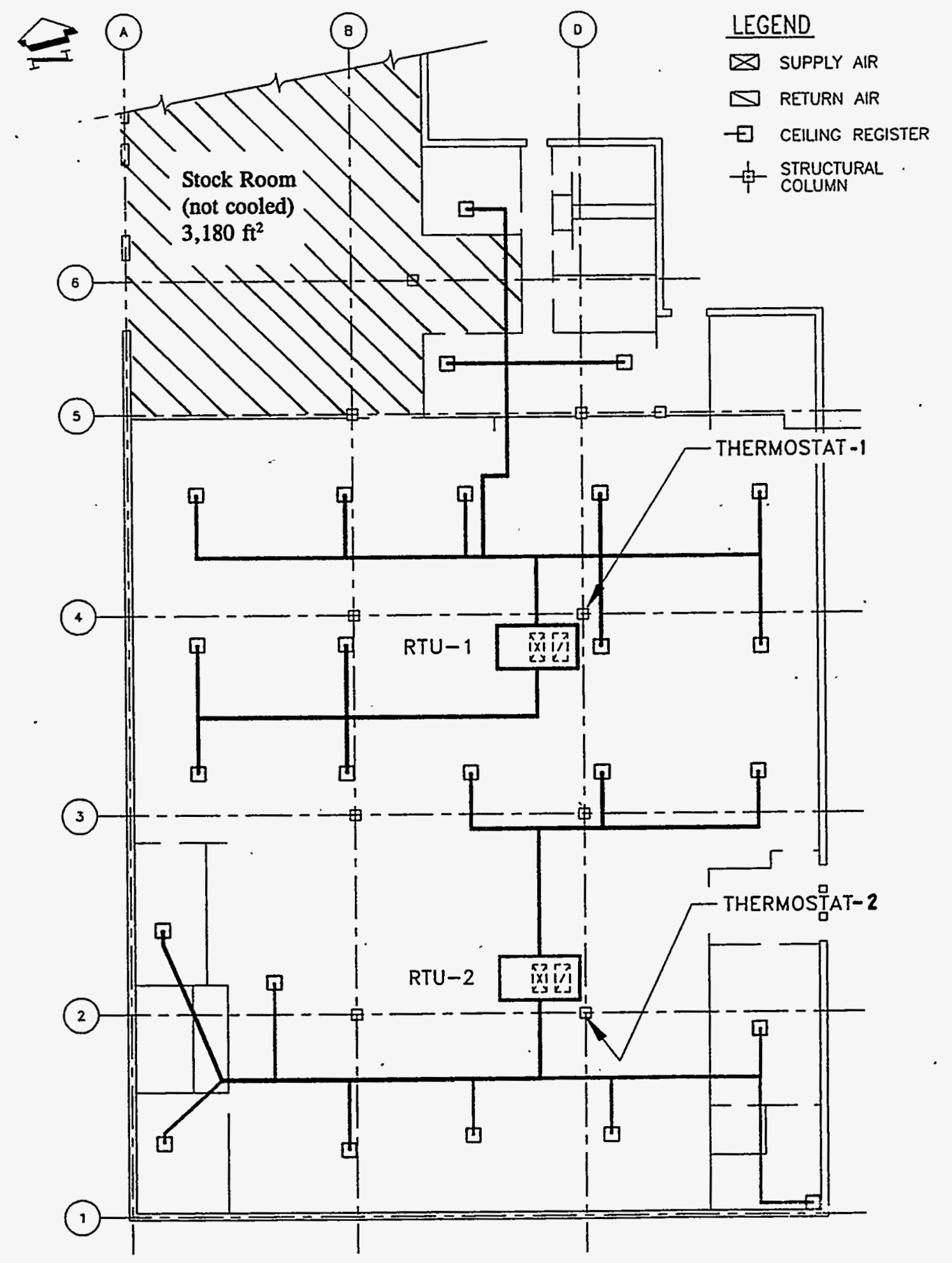

Figure 3.2. Location of Thermostat Controls in Relation to TK Units and Air Distribution Systems for the Retail Sales Area of $12,100 \mathrm{ft}^{2}$ 


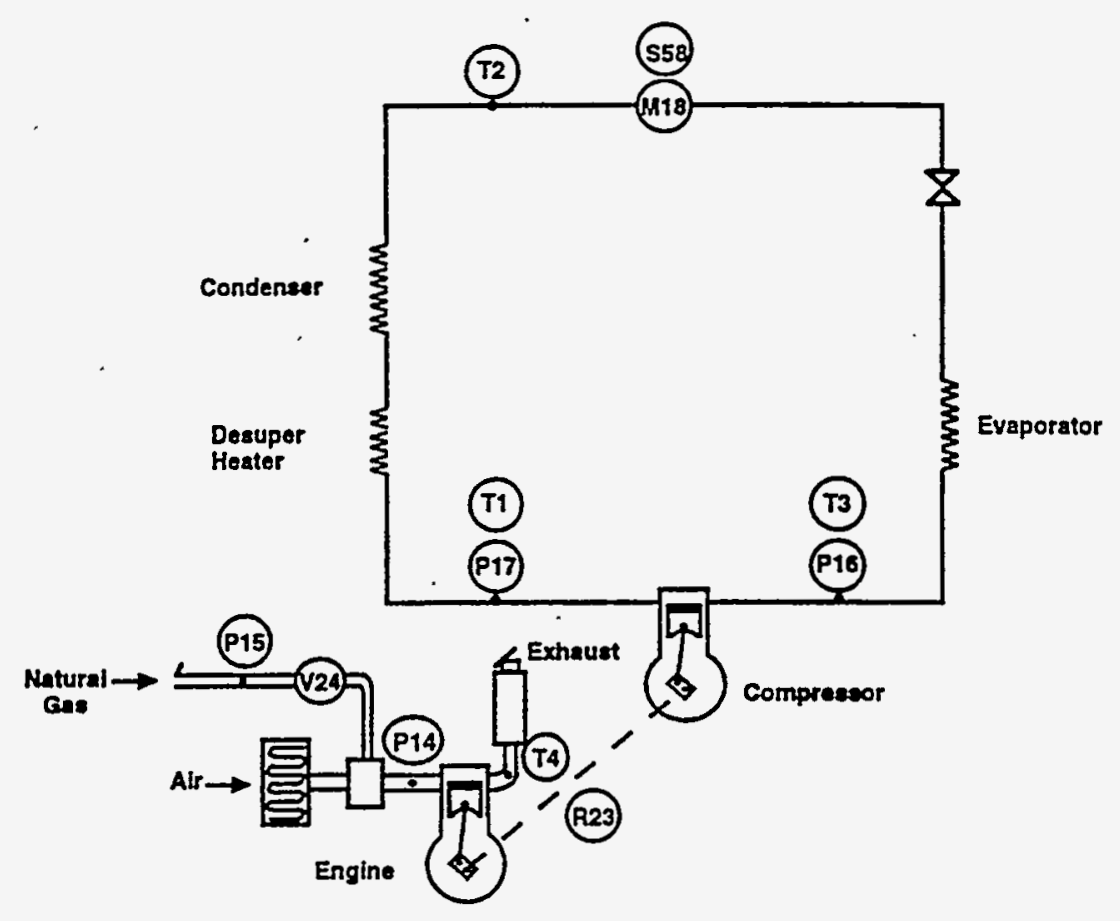

Figure 3.3. Sensor Locations in Refrigerant Loop

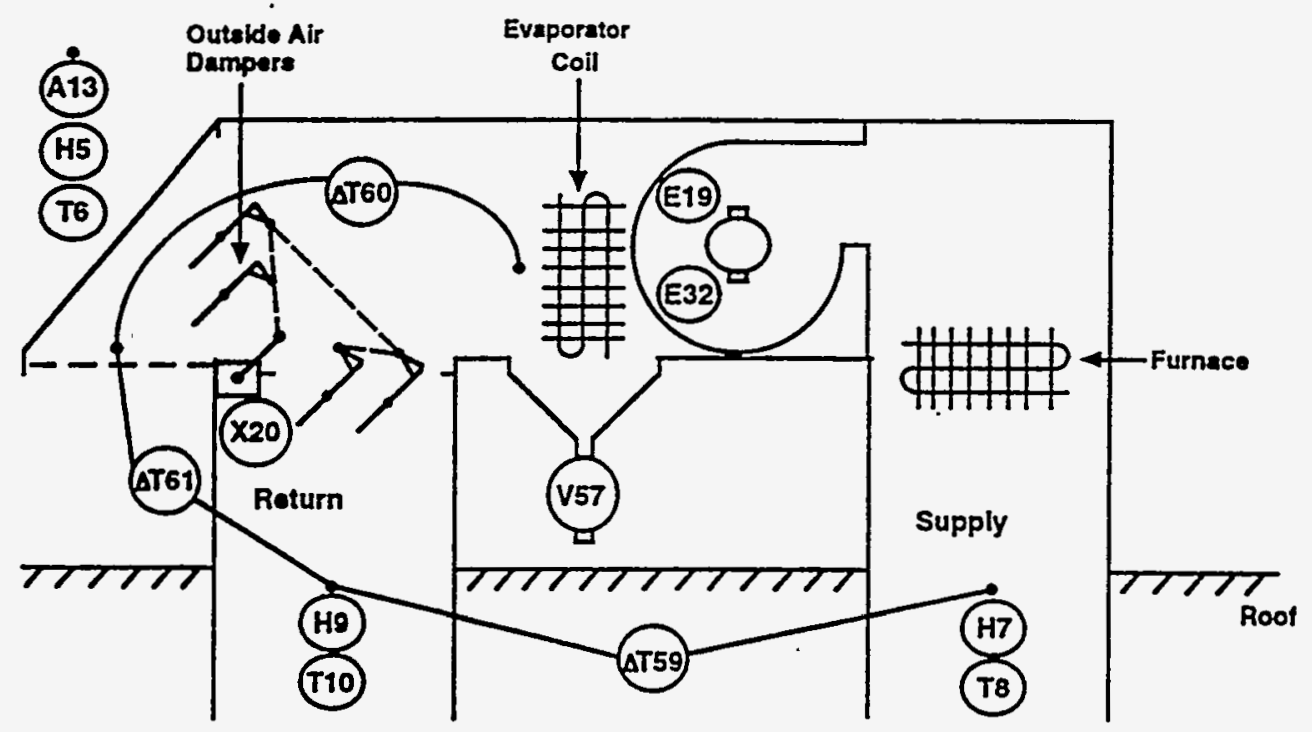

Building

Interior

(H11) (Near

(T12) Thermostat)

Figure 3.4. Sensor Locations in Zone and Air-Side Loop 
Table 3.1. Sensor Specifications

\begin{tabular}{|c|c|c|c|c|c|c|c|c|}
\hline (a) & int Description & $\begin{array}{l}\text { Input } \\
\text { Type }\end{array}$ & $\begin{array}{l}\text { Sensor } \\
\text { Range }\end{array}$ & $\begin{array}{c}\text { Normal } \\
\text { Range }\end{array}$ & Unit $^{(0)}$ & $\begin{array}{c}\text { Sensor } \\
\text { Type }\end{array}$ & $\begin{array}{c}\text { Sensor } \\
\text { Manufacturer }\end{array}$ & Sensor Model \\
\hline $\mathrm{Tl}$ & Discharge & $\mathrm{DE}$ & $-340 . .1112$ & $0 . .250$ & ${ }^{\circ} \mathrm{F}$ & Pt RTD & Hy-Cal & RTS-64-T-100-3-12-X1 \\
\hline T2 & Subcool & DE & $-340 . .1112$ & $0 . .150$ & ${ }^{\circ} \mathbf{F}$ & Pt RTD & Hy-Cal & RTS-64-T-100-3-12-XI \\
\hline T3 & Suction & DE & $-340 . .1112$ & $0 . .50$ & ${ }^{\circ} \mathrm{F}$ & Pt RTD & Hy-Cal & RTS-64-T-100-3-12-X1 \\
\hline T4 & Engine exhaust & DE & $-20 . .1000$ & $0 . .1000$ & ${ }^{\circ} \mathrm{F}$ & TC, type J & $\begin{array}{l}\text { Omega } \\
\text { Engineering }\end{array}$ & TJ36-CASS-116-12 \\
\hline T51 & T.C. reference & SE & $-13 . .122$ & $-13 . .122$ & ${ }^{\circ} \mathbf{F}$ & Thermistor & $\begin{array}{l}\text { Campbell } \\
\text { Scientific . }\end{array}$ & 10TCRT \\
\hline H5 & Outside air & SE & 0.100 & 0.100 & \%RH & Polymer & General Eastern & RHT-2-1-OA \\
\hline T6 & Outside air & SE & $-20 . .140$ & $-20 . .100$ & ${ }^{\circ} \mathrm{F}$ & Pt RTD & General Eastern & RHT-2-1-OA \\
\hline H7 & Supply air & SE & $0 . .100$ & $0 . .100$ & \%RH & Polymer & General Eastern & RHT-2-I-R \\
\hline T8 & Supply air & SE & $-20 . .140$ & $50 . .140$ & ${ }^{\circ} \mathrm{F}$ & Pt RTD & General Eastern & RHT-2-I-R \\
\hline н9 & Return air & SE & $0 . .100$ & $0 . .100$ & $\% \mathrm{RH}$ & Polymer & General Eastern & RHT-2-I-R \\
\hline T10 & Return air & SE & $-20 . .140$ & $60 . .80$ & ${ }^{\circ} \mathrm{F}$ & Pt RTD & General Eastern & RHT-2-I-R \\
\hline H11 & Room air & SE & $0 . .100$ & $0 . .100$ & \%RH & Polymer & General Eastern & RHT-2-1-S \\
\hline T12 & Room air & SE & $-20 . .140$ & $60 . .80$ & ${ }^{\circ} \mathrm{F}$ & Pt RTD & General Eastern & RHT-2-I-S \\
\hline A13 & Barometer & SE & 0.25 & 14.5..15 & psia & strain gage & Setsa & C280E \\
\hline P14 & Intake vacuum & SE & $0 . .10$ & $0 . .5$ & psig & strain gage & Setra & C239 \\
\hline A15 & Gas supply & SE & 0.25 & 14.5..15 & psia & strain gage & Setra & C280E \\
\hline P16 & Compressor suction & SE & $0 . .250$ & 50.200 & psig & strain gage & Setra & C207 \\
\hline P17 & Compressor dischg & SE & $0 . .500$ & 150.350 & psig & strain gage & Setra & $\mathrm{C}_{207}$ \\
\hline M18 & Refrigerant flowrate & SE & $0 . .60$ & $5 . .45$ & ppm & inertial & Micromotion & $D-40-119$ \\
\hline E19 & Total electric power & $S E$ & $0 . .6000$ & $0 . .4000$ & w & Hall effect & Ohio Semitronic & WOE-23ET/60K \\
\hline $\mathrm{x} 20$ & $\begin{array}{l}\text { Outside air damper } \\
\text { opening }\end{array}$ & SE & 0.2400 & 0.2400 & $\mathrm{mV}$ & pot & Honeywell & Q181A-1007 \\
\hline $\mathbf{R} 23$ & Engine RPM & $\mathbf{P}$ & $0 . .5000$ & 0.2600 & $\mathbf{r p m}$ & magnetic & Transwise & XP160-SPI53-ISO \\
\hline V24 & Gas ACFH & $\mathbf{P}$ & $0 . .1000$ & $0 . .300$ & cfh & PD lobe & Dresser/Roots & 8C-175psig-050932-101ce \\
\hline S25 & Cooling step 1 & IN & $1=O N$ & $0 . .900$ & s & LED Relay & Stevens Engrg & RH2B-UL-AC24V \\
\hline S26 & Cooling step 2 & IN & $1=O N$ & $0 . .900$ & $\mathbf{s}$ & -LED Relay & Stevens Engrg & RH2B-UL-AC24V \\
\hline S27 & Cooling step 3 & IN & $1=0 N$ & $0 . .900$ & $\mathbf{s}$ & LED Relay & Stevens Engrg & RH2B-UL-AC24V \\
\hline S28 & Cooling step 4 & IN & $1=O N$ & 0.900 & $\mathbf{s}$ & LED Relay & Stevens Engrg & RH2B-UL-AC24V \\
\hline S29 & Heating step 1 & IN & $1=O N$ & 0.900 & $\mathbf{s}$ & LED Relay & Stevens Engrg & RH2B-UL-AC24V \\
\hline S30 & Heating step 2 & IN & $1=\mathrm{ON}$ & $0 . .900$ & $\mathbf{s}$ & LED Relay & Stevens Engrg & RH2B-UL-AC24V \\
\hline S31 & Engine enable & IN & $1=\mathrm{ON}$ & $0 . .900$ & $\mathbf{s}$ & LED Relay & Stevens Engrg & RH2B-UL-AC24V \\
\hline E32 & Electric power pulse & $\mathbf{P}$ & $0 . .1500$ & $0 . .1000$ & Wh & Hall effect & Ohio Semitronic & WOE-23ET/60K \\
\hline DT61 & Return-outsideair & $\mathrm{DE}$ & $+1-200$ & $+1-25$ & ${ }^{\circ} \mathbf{F}$ & TP, type T & C.S. Gordon & T24-2-505 \\
\hline DT60 & Mixed-outsideair & DE & $+1-200$ & $+1-75$ & ${ }^{\circ} \mathrm{F}$ & TP, type T & C.S.Gordon & $T 24-2-505$ \\
\hline DT59 & Supply-returnair & DE , & $+1-200$ & $+1-75$ & ${ }^{\circ} \mathrm{F}$ & TP, type T & C.S. Gordon & T24-2-505 \\
\hline V57 & Condensate drain & $\mathbf{P}$ & $0 . .10$ & $0 . .1$ & pps & tip bucket & Texas Electronics & 501 \\
\hline \multicolumn{9}{|c|}{ 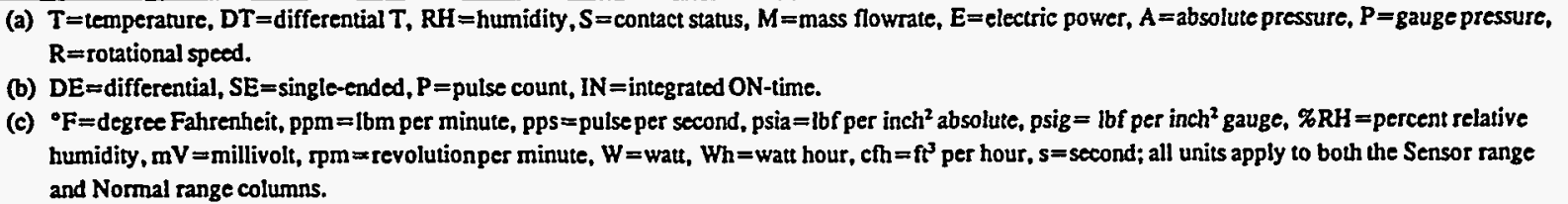 } \\
\hline
\end{tabular}




\subsection{Observed Performance and Operation}

The gas-powered air-conditioning units were monitored starting June 18, 1992, and monitoring continued through the 1993 cooling season. This continued monitoring was used to assess heating season performance as well as to assess performance during an additional cooling season. The data used in the 1992 cooling season analysis were limited, for the most part, to the period from July 11 through September 14, 1992. Data for the months of October through March were used in the 1992/93 heating season analysis. Observation of performance in the first cooling season showed that improved seasonal COP and fewer engine starts could be obtained by coordinating the control of the two rooftop units (RTUs). The CRADA partners agreed to test this hypothesis in the 1993 cooling season and the site placed a work order to install a supply air duct crossover so that the entire NEX distribution system could be fed by one RTU. Maintenance and repair demands elsewhere on the site prevented completion of this work; however. Instead, monitoring continued through the 1993 cooling season to confirm the evaluation of 1992 cooling-season performance.

\subsection{Cooling Loads}

A model is needed to extrapolate field evaluation data to a normal weather year. The easiest to measure indicator of cooling load is input energy used to operate the compressor and condenser fan. The supply fan energy is only a weak function of cooling load, since it runs continuously during occupied hours. The total rate of natural gas use is, therefore, the input energy stream of interest. The daily average rates of gas input to the two units (based on $1040 \mathrm{Btu} / \mathrm{scf}$ ) in 1992 are shown in Figure 4.1, along with the daily mean outdoor temperature history. The input load is clearly correlated with outside temperature. Notice, however, that Unit 2 uses almost twice as much natural gas as Unit 1.

The load imbalance problem was observed in early July, 1992, during a site visit and was attributed to a small difference in the thermostat setpoints within the building. The thermostats are set by the building manager to satisfy employees' comfort needs. However, even if the same nominal setpoint is used on both thermostats, a small setpoint difference can result in a large load imbalance because the two units serve the same zone. (It might be more appropriate to control both units from a single thermostat to ensure load balance.) In this situation, it is likely that the total zone load will be better correlated with outdoor temperature than will the load of either of the units that serve the zone.

The daily average rates of gas input to the two units in the 1993 cooling season are shown in Figure 4.2. As in 1992, the input load is fairly well correlated with outside temperature. In the first half of the summer, load distribution is not well balanced with Unit 2 taking most or all of the load on some days and Unit 1 taking the load on others. In the second part of the summer the load is much better balanced but we have not been able to determine the reason for this improvement. 


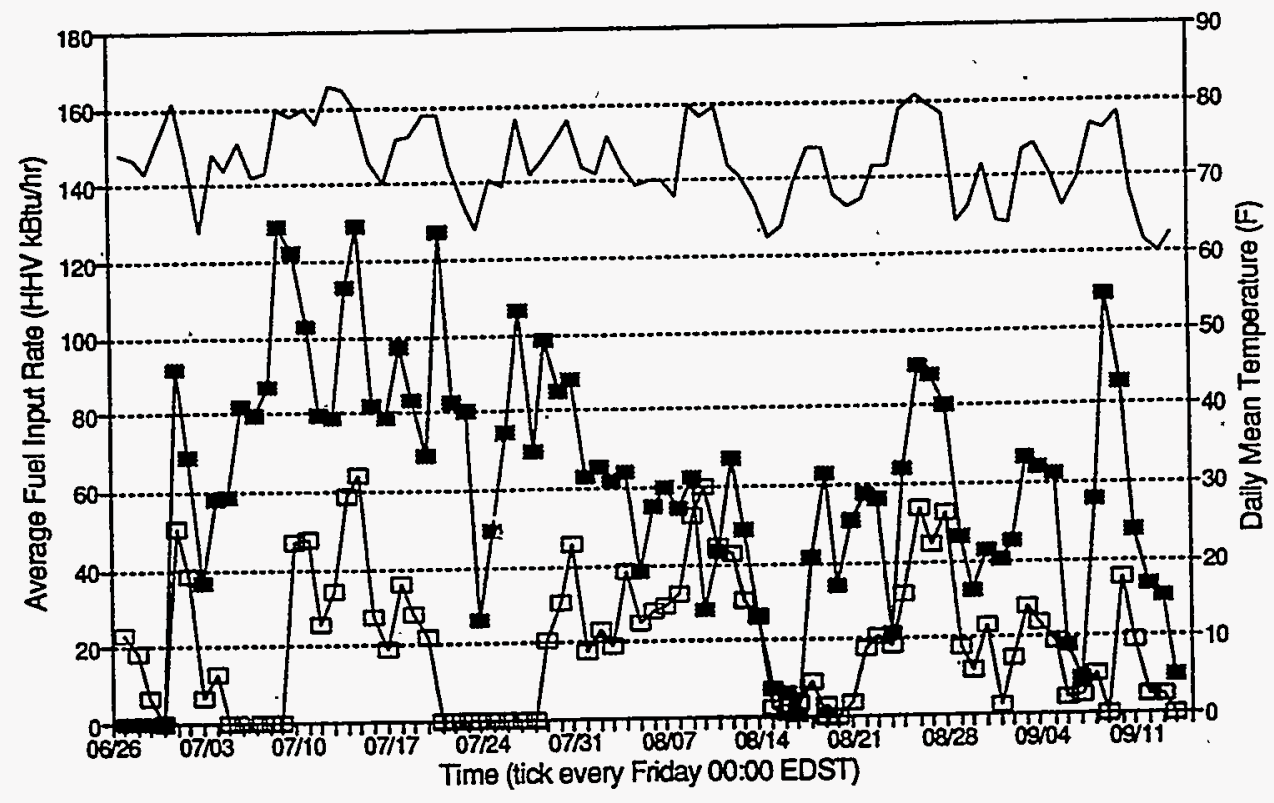

Figure 4.1. Daily Average Fuel Input and Temperature in the 1992 Cooling Season

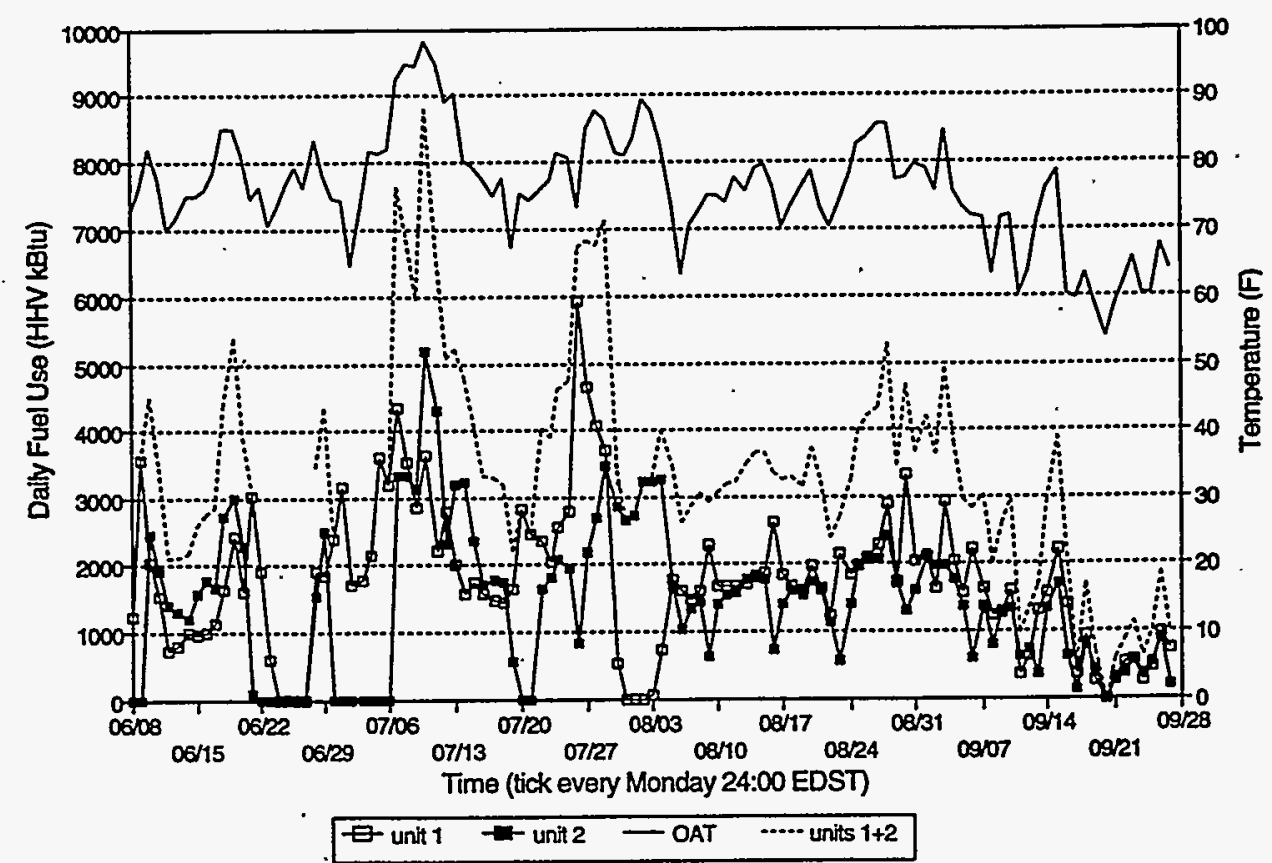

Figure 4.2. Daily Average Fuel Input and Temperature in the 1993 Cooling Season 
Figure 4.3 shows the daily gas loads for Units 1 and 2 combined as a function of ambient temperature. The load range in 1993 is much greater than in 1992; the relation between input energy and mean daily outdoor temperature for the range of temperatures experienced in 1992 is essentially identical in 1993. The relationship for the region of the high loads experienced in 1993, but not in 1992, is somewhat steeper. This change is expected because the COPs are lower at high loads.

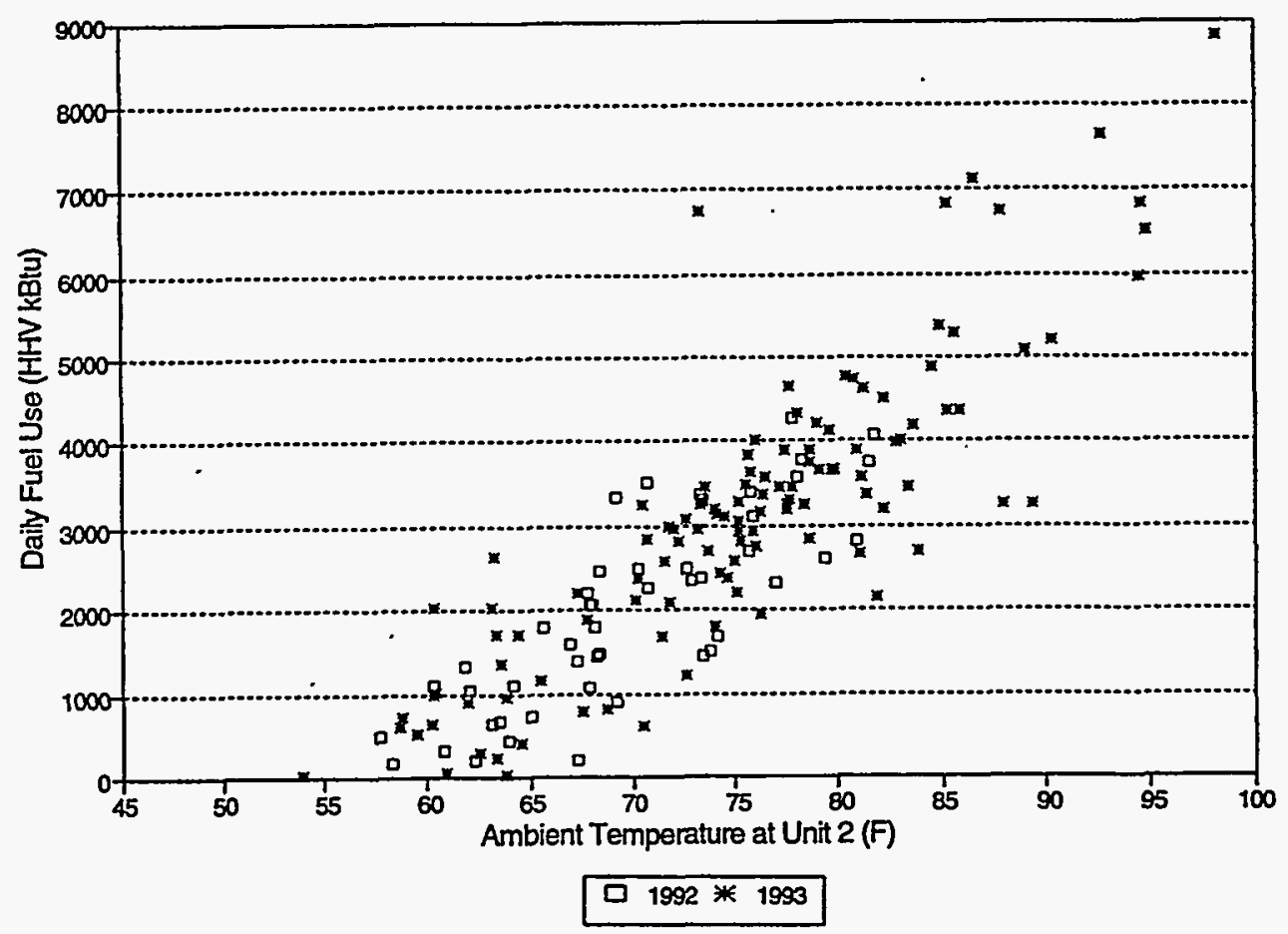

Figure 4.3. Relation Between Cooling-Mode Fuel Use and Mean Daily Temperature

\subsection{Cooling Efficiency}

The coefficient of performance (COP) for Unit 1 was computed from air-side sensible and latent loads and gas input energy rate measured in 1992.(a) Note that the compressor and condenser and engine fan energy inputs are included in this definition but that the supply air (indoor) fan energy is not. Figure 4.4 shows the average daily COP in each cooling stage. The COP is relatively constant in each cooling stage ( $\mathrm{C} 1$ through $\mathrm{C} 4$ ), ranging between 0.5 and 0.6 in $\mathrm{C} 1$, between 0.8 and 1.0 in $\mathrm{C2}$, between 0.65 and 0.75 in $\mathrm{C} 3$ and between 0.5 and 0.6 in C4. Also shown is the average daily load and overall daily average COP. The overall daily COP tracks C1 COP on most days but improves on higher load days because of the influence of $\mathrm{C} 2$ and $\mathrm{C} 3$ COPs.

The measured COPs are compared to the COPs quoted by the manufacturer (Thermo King 1990, p. 25) in Figure 4.5. The middle bar in each group reflects COPs measured during the period after

(a) COPs could not be determined in 1993 because all low-level signals were found to have been biased when a shunt in a 4-2ma pressure sensor loop failed. However, the data presented in Figure 4.3 indicate that there was no significant change in COP between 1992 and 1993. 


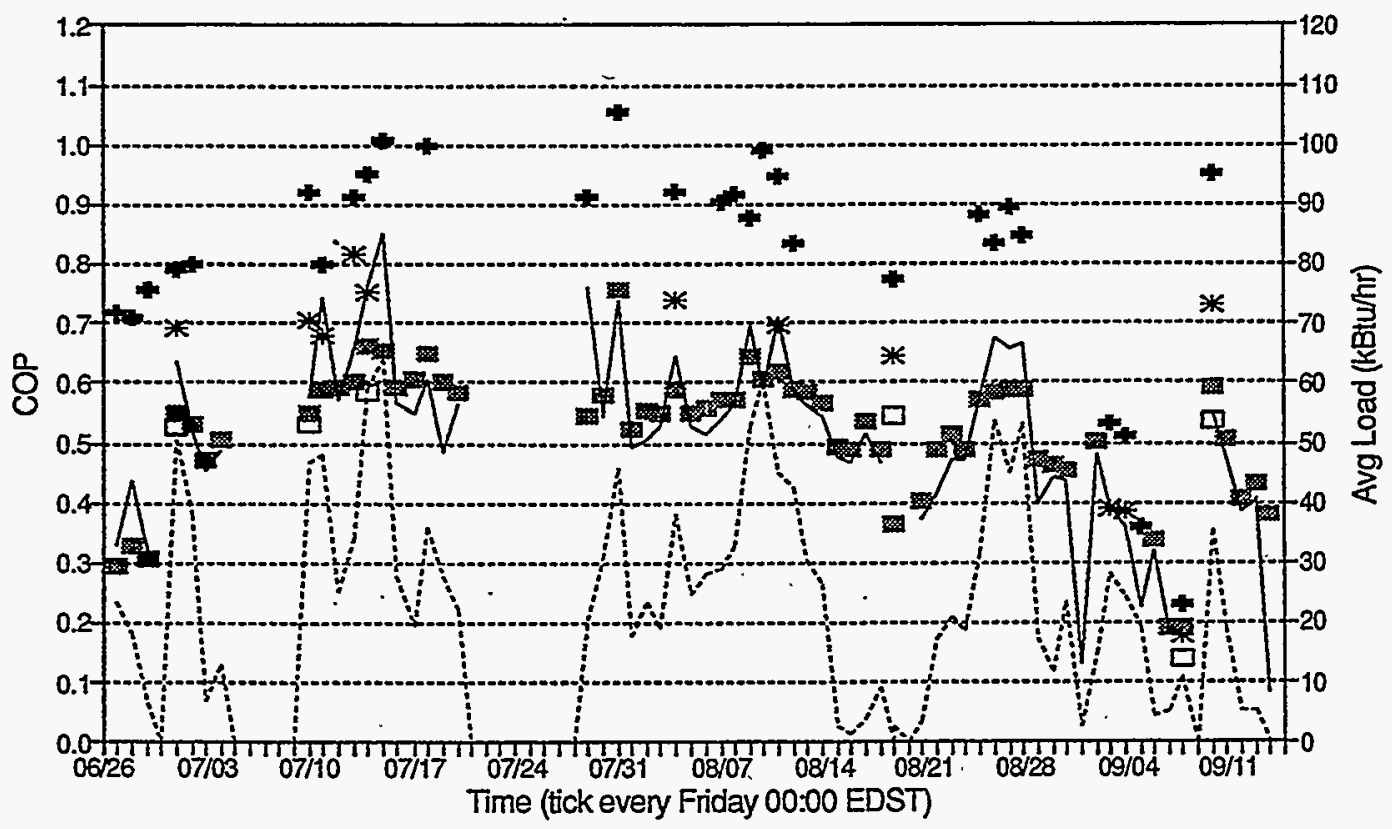

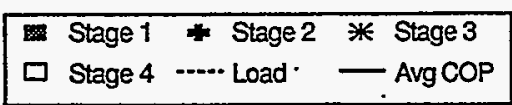

Figure 4.4. Average Daily COP by Cooling Stage Measured in 1992

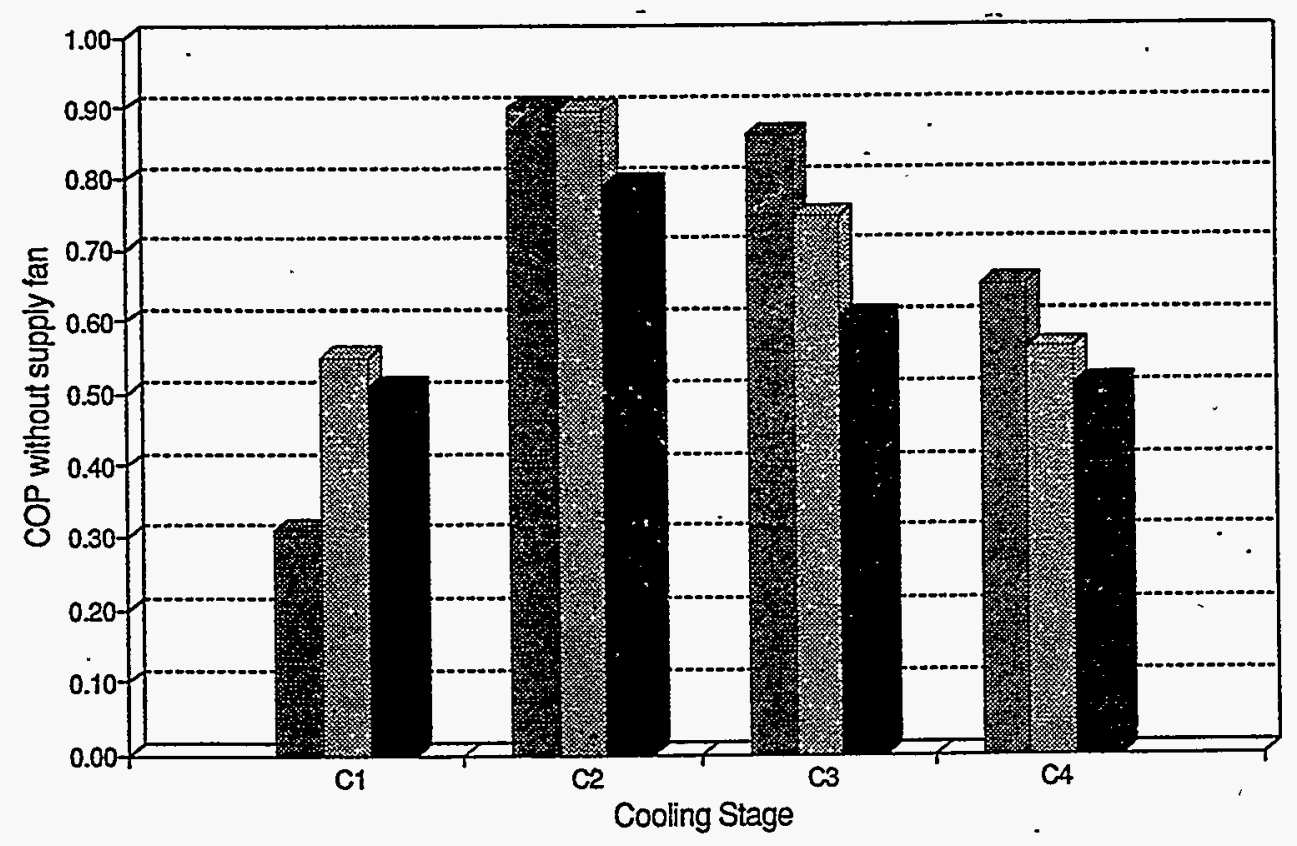

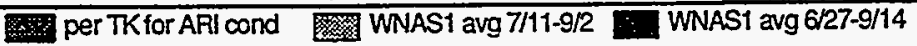

Figure 4.5. 1992 Measured COPs of Unit 1 Versus Manufacturer's COP Ratings 
Unit 1 had been purged of non-condensibles, was properly charged with refrigerant, had its evaporator coil splitter solenoid disabled, and was subject to large daily cooling loads that minimized engine starts/stops and other operational transients. In this period the C1 COP was almost double the quoted value, the C2 COP was very close to the quoted value, and the C3 and C4 COPs were both about $10 \%$ less than the quoted values. The average COPs over the longer period were about $10 \%$ lower than the COPs measured in the shorter period and show the effects of imperfect maintenance and control as well as the effect of transient operation that is more prevalent later in the cooling season.

The seasonal COP is; in simplest terms, the sum of the part-load COP and part-load operating time products divided by the total operating time. The seasonal COP for unit 1 is substantially lower than the integrated part-load value (IPLV) quoted, due mainly to longer operation in C1 and shorter operation in C2 relative to the IPLV shares of operating time assumed in the manufacture's seasonal COP estimate. Figure 4.6 shows the part-load operating time distributions for Units 1 and 2 along with the operating time distribution used by the manufacturer to compute seasonal COP for typical applications.

The Thermo King units consumed 190 million Btu (MBtu) of fuel (based on the higher heating value of natural gas) and provided 115 MBtu of cooling effect to the NASWG NEX during the 1992 cooling season monitoring/analysis period. Efficiency could not be measured directly during the 1993 cooling season because a pressure transducer failure induced errors in the microvolt signals produced by the air-side thermopiles. However, the building load-temperature correlation provides a means of comparing performance under the different load conditions experienced in the 1992 and 1993 cooling seasons. Using this approach, fuel consumption in the 1993 cooling season of $367 \mathrm{MBtu}$ (HHV) is expressed in weather normalized terms as $195 \mathrm{kBtu} /\left({ }^{\circ} \mathrm{Fday}\right)$, which is essentially unchanged from the 1992 performance.

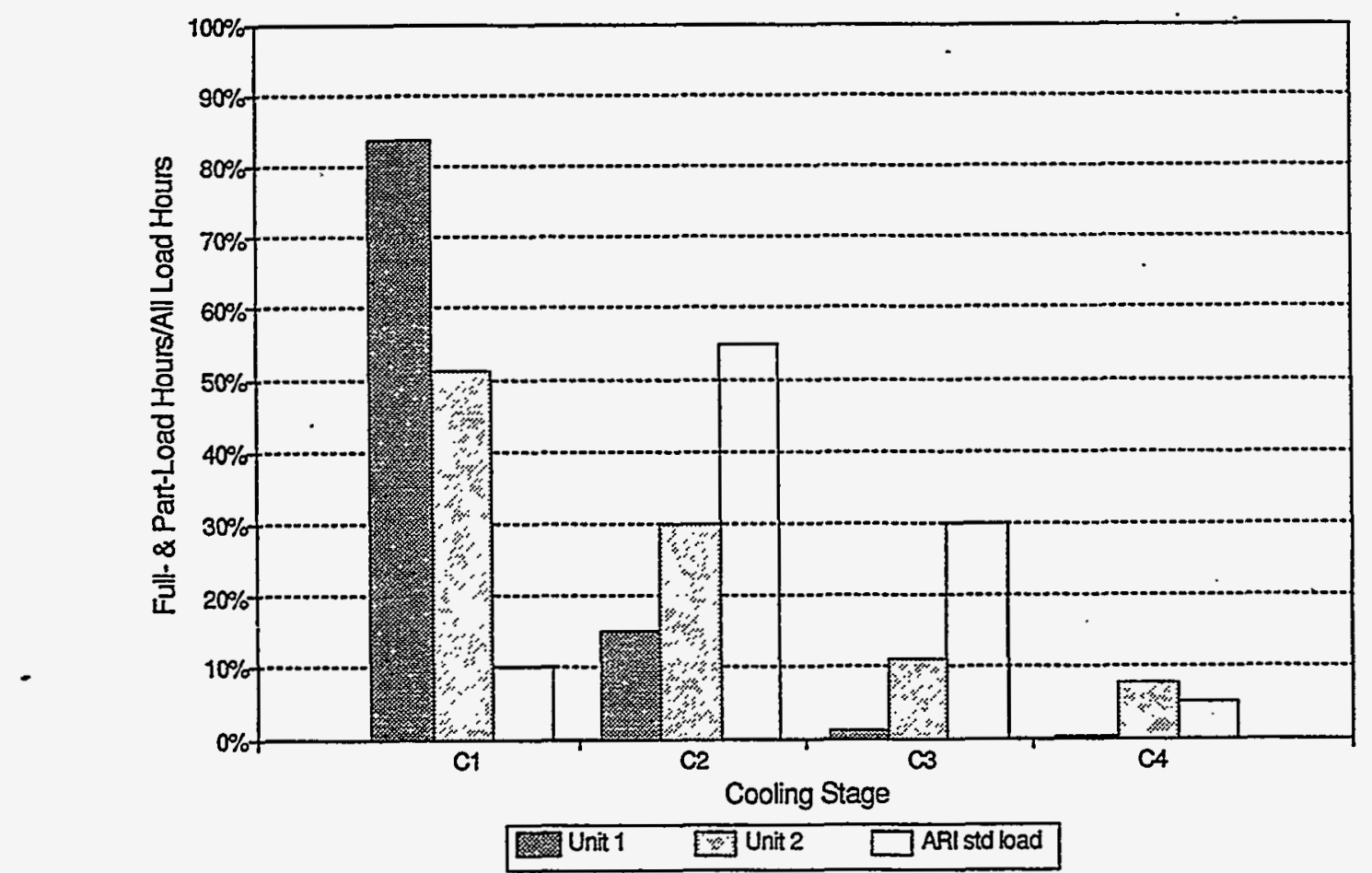

Figure 4.6. Unit 1·Measured Part-Load Operating Times Versus Those Used by the ARI Standard to Compute Seasonal COP 


\subsection{Cooling Operational Improvements}

A number of opportunities for improved operation were identified through analysis of the field performance data.

Scheduling. The programmable thermostats provide seven-day scheduling of heating and cooling setpoints and fan operation. The NEX operates from 8:00 am to 6:00 pm Tuesday through Friday and from 10:00 pm to 6:00 pm Saturday and Sunday. The NEX is closed on Monday. The daily profiles in Figure 4.7 indicate that the thermostats are not correctly programmed for unoccupied operation from 00:00 am Monday through 07:00 am Tuesday. The cooling season savings that will be realized by correcting the schedule programs are about $40 \mathrm{MBtu} / \mathrm{yr}$ in cooling fuel, as indicated in Figure 4.8 , and about $860 \mathrm{kWh} / \mathrm{yr}$ in fan energy, as indicated in Figure 4.7.

Economizer Operation and Control. Figure 4.9 shows the effect on daily cooling load of economizer operation. The large incidence of increased load is due to the latent load associated with outside air on days when outside air is cooler, but more humid, than return air. Retrofit of differential enthalpy based economizer controls in both units will result in an annual savings of about $3 \mathrm{MBtu} / \mathrm{yr}$ and eliminate periods of excessive indoor humidity that sometimes occur with the existing controls.

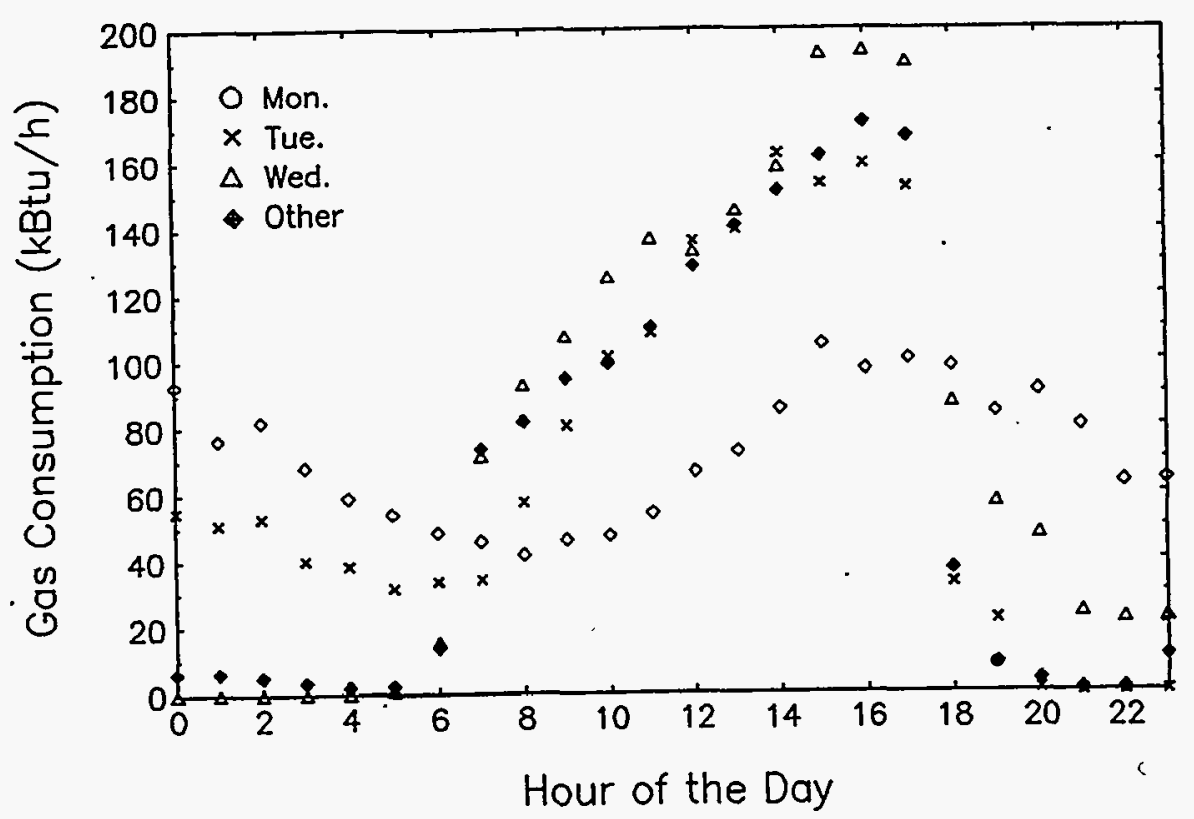

Figure 4.7. Average Day Load Profiles in the Cooling Season 


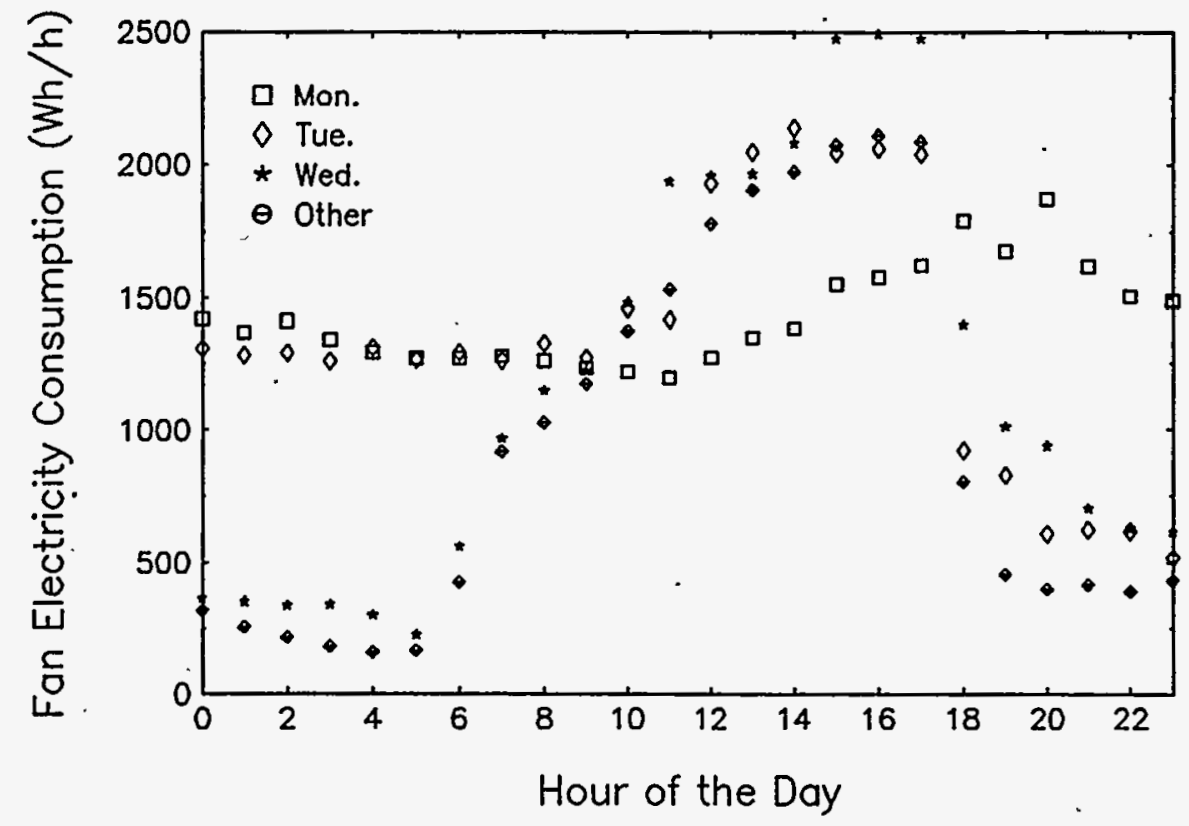

Figure 4.8. Average Day Fan Energy Use in the Cooling Season

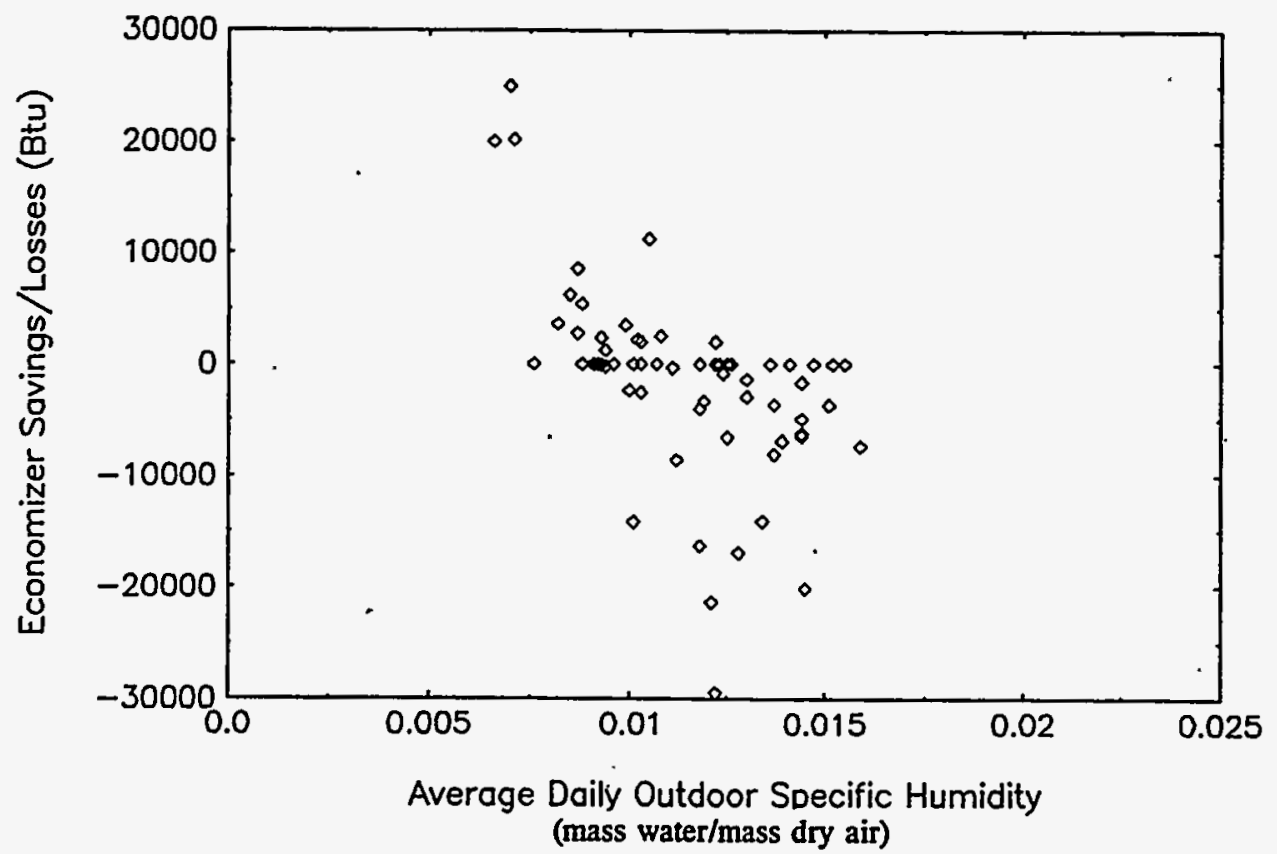

Figure 4.9. Reduction in Daily Cooling Load that Resulted from Economizer Operation 
Coordination and Staging. Unit 2 provided more cooling than Unit 1 throughout most of the test period. There was no indication, however, that this was due to a significant difference in load between the areas served by the two units. Rather, the cooling load imbalance was most likely caused by the thermostat location or a small difference in setpoint. Connecting the two distribution systems to form a single-zone distribution system would likely not result in a noticeable degradation in temperature and humidity uniformity.

A single-zone system would have three benefits in this application. First, redundancy would be provided. If one of the two units failed (as happened) the loss of capacity would be spread over the entire zone with no resulting "hot spot." Second, equal wear of the two units would be ensured. The units could be operated in an alternating lead-lag arrangement for light loads and in tandem for heavy loads. Third, improved efficiency could be realized. Many times, Unit 1 cycled between stage 1 and 2 cooling while Unit 2 cycled between stage 2 and 3 cooling. The aggregate load could have been met by operating both units at stage 2 , the most efficient stage. Similarly, many times Unit 1 cycled between off and stage 1 cooling while Unit 2 cycled between stage 1 and stage 2 cooling. The aggregate load could have been met by operating one of the units at stage 2 , the most efficient stage, most of the time.

\subsection{Heating}

Heating has historically been, and continues to be, a relatively small part of the operational cost of Willow Grove facilities. However, heating costs may be more significant at other sites where application of this new technology is attractive.

\section{Heating Efficiency}

The fuel consumption for heating was essentially equal to the fuel consumption that would have occurred using comparable gas heating/electric cooling rooftop units in place of the subject units. Daily fuel use in the 1992-93 heating season responded to mean daily outdoor temperature as shown in Figure 4.10. The data suggest a balance point of about $67^{\circ} \mathrm{F}$ on Mondays (NEX closed) and $53^{\circ} \mathrm{F}$ on days when the NEX was open for business. A specific fuel rate of about $60 \mathrm{kBtu}$ per ${ }^{\circ} \mathrm{F}$-day is also apparent. Total heating energy for the $1992-93$ season was $159 \mathrm{MBtu}$ of fuel. The measured annual heating efficiency was $80 \%$, which is consistent with the $81 \%$ rating quoted by the manufacturer.

\section{Heating Operational Improvements}

A number of opportunities for improved operation were identified through analysis of the data.

Scheduling. The programmable thermostats provide seven-day scheduling of heating and cooling setpoints and fan operation. The NEX operates from 8:00 am to 6:00 pm Tuesday through Friday and from 10:00 pm to 6:00 pm Saturday and Sunday. The NEX is closed on Monday. The daily fan energy profiles in Figure 4.11 indicate that the thermostats are not correctly programmed for 


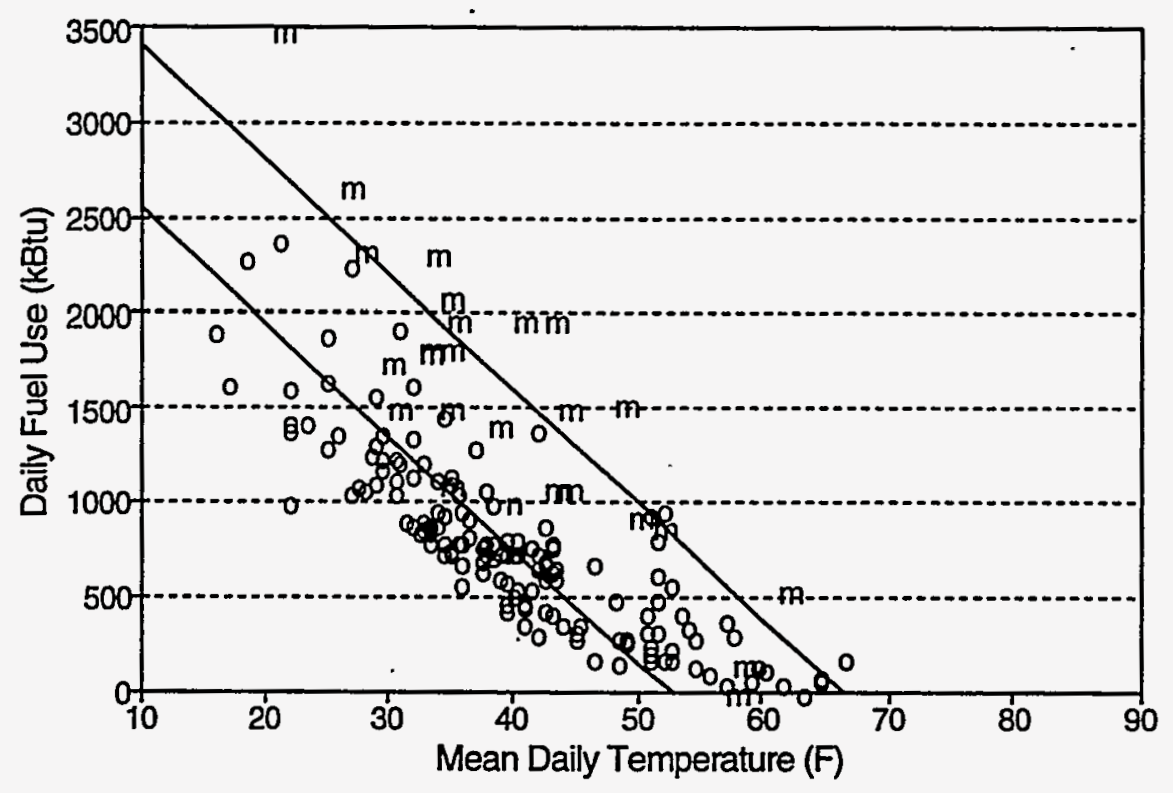

Figure 4.10. Relations Between Daily Fuel Used for Heating and Mean Daily Temperature; Mondays are indicated by " $\mathrm{m}$ " and all other days by " $\mathrm{o}$ "

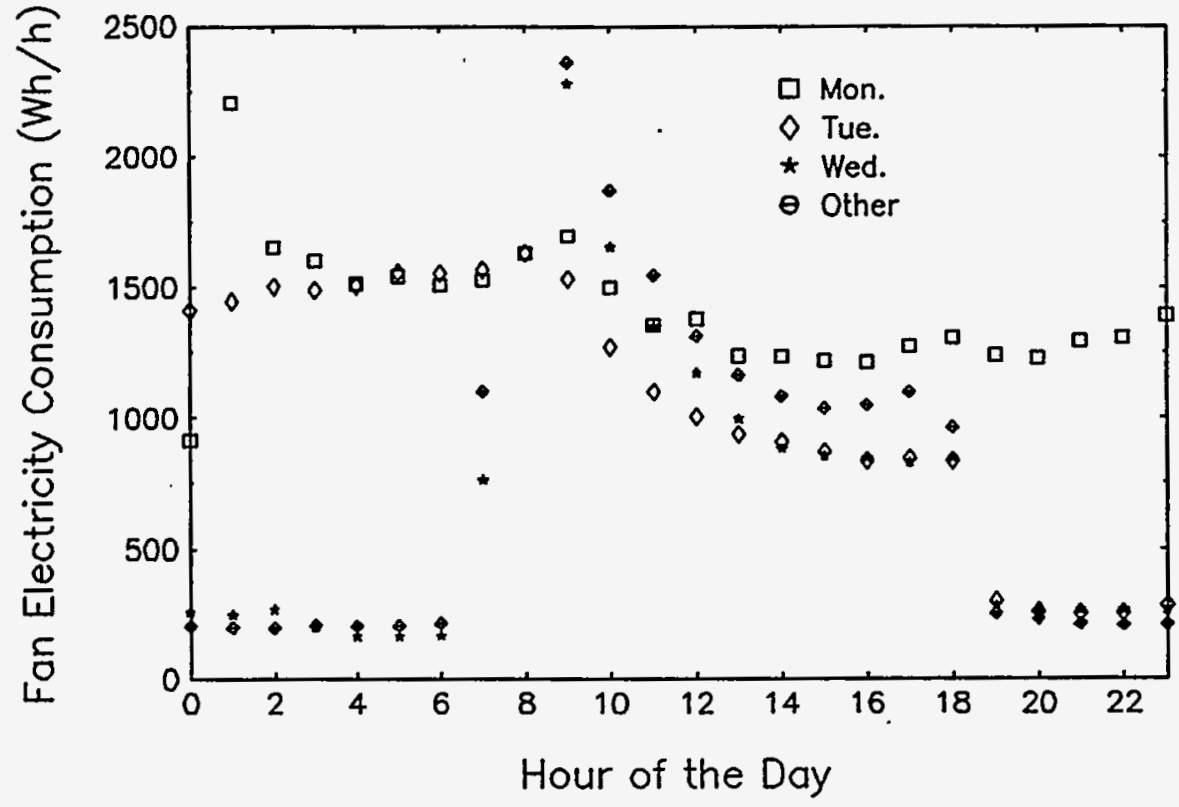

Figure 4.11. Average Day Fan Energy Use Profiles in the Heating Season 
unoccupied operation from 00:00 am Monday through 07:00 am Tuesday. The heating energy wasted by this scheduling error is indicated qualitatively in Figure 4.12. From the regression model, the heating season savings that will be realized by correcting schedules are about $52 \mathrm{MBtu} / \mathrm{yr}$ in heating fuel and about $1,300 \mathrm{kWh} / \mathrm{yr}$ in fan energy.

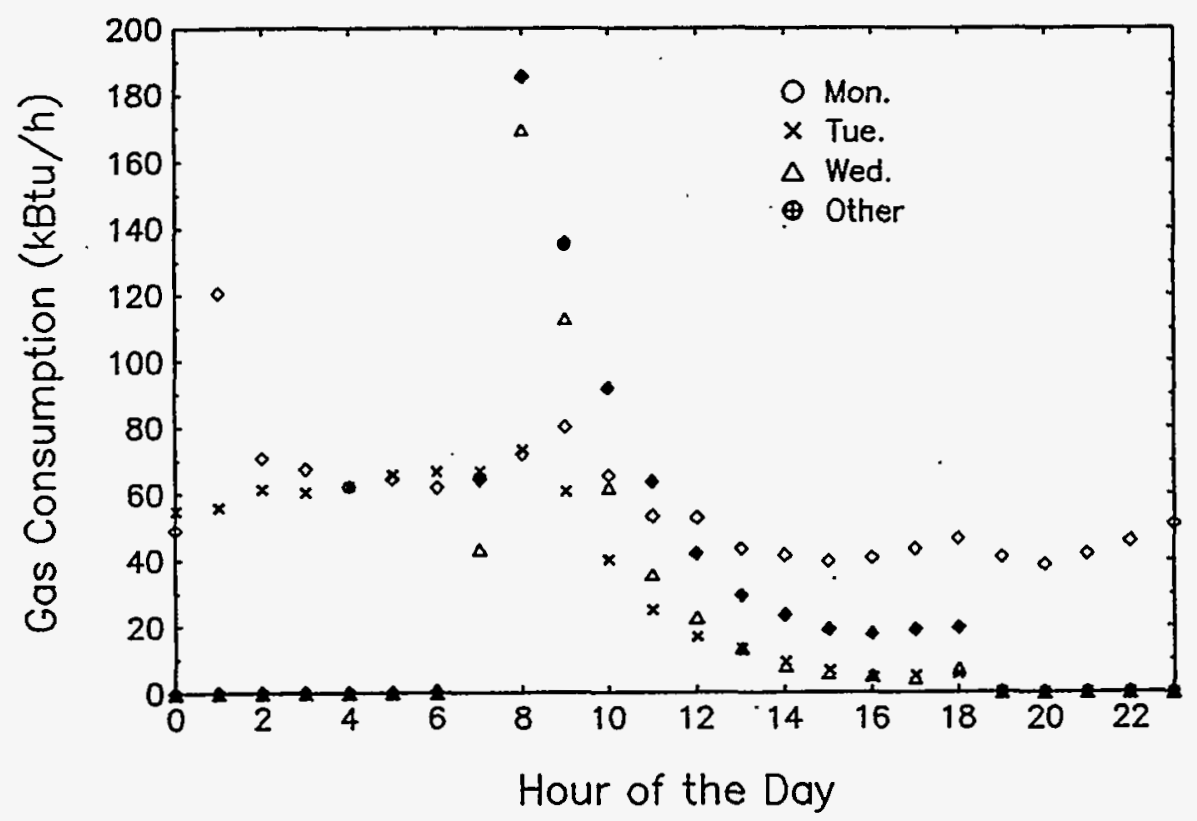

Figure 4.12. Average Day Fuel Use Profiles in the Heating Season

\subsection{Lessons Learned}

Preventive Maintenance. Most of the operational problems observed at the NEX can be avoided at very low cost by making minor additions to the preventive maintenance program. The checklist for spring maintenance should include-in addition to engine, fan, filter, condensate drain, and coil maintenance-the following checks: economizer sensors, actuator, linkage, dampers and overall economizer control; minimum outside air setting; distribution system (obstructions and leaks) and building pressurization; thermostat setpoint and fan schedules.

Design Considerations. Because of the high first cost, it is important not to oversize the gas-powered unit. While capacity modulation between 40 and $100 \%$ of gas-engine-driven units' rated capacity is very simple and desirable from an efficiency perspective, modulation below about $40 \%$ is not (Armstrong and Conover 1993)., Under light loads, the unit must cycle on and off, which wears out the engine, or operate inefficiently. Thus oversizing increases long-term maintenance cost or energy cost, as well as increasing the already substantial first cost. 
The use of zoning with multiple rooftop units may be effective in applications like the NEX where the design cooling load requires two or more units on one roof. With a crossover connection and damper between the two existing NEX duct systems, a single unit can be used to satisfy the entire load most of the time.

The staging and zoning problems observed in the test indicate that the application of gas-enginedriven rooftop units is less forgiving than the application of conventional electric rooftop units. This problem is not peculiar to the subject technology but is common to many new energy-efficiency technologies. In fact, greater attention to design details is itself one of the most cost-effective paths to higher energy efficiency in buildings. 


\subsection{Annual Performance and Life-Cycle Cost}

The economic analysis was performed in four steps. First, monitored cooling loads were extrapolated to a normal weather year. Second, performance of a comparable electric chiller was estimated for the monitoring period. Third, input energy requirements of the gas powered unit and the comparable electric powered unit were extrapolated to a normal year cooling season. Fourth, and last, annual energy numbers and other pertinent cost and economic parameters were used to estimate life-cycle costs of the two alternatives.

\subsection{Base-Case Definition}

The decision to invest in a new technology cannot be made without evaluating one or more suitable existing technologies. It was necessary to model the performance of an equivalent electric-powered unit for three reasons. First, model-based adjustments are almost always needed in a field performance comparison because the conditions imposed on the test articles in question are different regardless of whether a side-by-side or before-after monitoring protocol is employed. Second, an equitable comparison between gas and electric technologies could not have been obtained from such field monitoring without making substantial adjustments for performance degradation due to equipment age and performance improvements that technology and design evolution have wrought in the years since the previous units were manufactured and installed. And third, there was no opportunity to determine the field performance of the old electric-powered rooftop units because they were removed prior to installation of the TK units and before NASWG became involved with the New Technology Demonstration Program.

To compare electric and gas technologies as equitably as possible and to avoid uncertainties about the field (as opposed to theoretical) performance of a "comparable" electric unit, only the prime movers were modeled. Thus, the comparable electric unit was assumed to be identical to the gas unit in all of its conventional parts-i.e., its compressor, coils and air-side components and controls--and is modeled as a TK unit with the engine replaced by a 30-hp compressor motor and a 2-hp condenser fan motor. The single-speed premium energy-efficient motor efficiencies quoted by Nadel (1991) are assumed, optimistically, to prevail in all four cooling stages, and the engine efficiencies quoted by TK are used to convert natural gas input rates measured in the four cooling stages to corresponding shaft loads. ${ }^{\text {(a) }}$

(a) Note that stage 1 cooling is implemented by cylinder unloading just as it is in the gas-powered unit. It might be more realistic to model the comparable electric unit with a small separate hermetic motor/compressor to implement stage 1 cooling. However, introducing the more efficient stage 1 implementation makes analysis of the electric unit's energy consumption much more complex and would not change the life-cycle cost by more than a few percent because monthly ratchet charges (which constitute over $70 \%$ of the annual operating cost) would not be affected. 
With the foregoing assumptions, the energy and demand requirements of the comparable electric units can be evaluated for the monitoring period. To complete the life-cycle cost analysis, however, it is necessary to estimate the annual energy requirements of the gas-powered units as well as the annual energy and demand requirements of the comparable electric units. The analysis required to make this extrapolation is presented below.

\subsection{Normal Year Loads}

The cooling load is predominantly a sensible cooling load, well correlated with mean daily temperature. The balance point (temperature above which a cooling load exists) is about $60^{\circ} \mathrm{F}$. Base $65^{\circ} \mathrm{F}$ Cooling Degree Days (CDD) tabulated in NAVFAC P-88 (TM 5-785) are 946 CDD for NASWG. The corresponding numbers for nearby locations in Pennsylvania, New Jersey and Delaware are: 1104 CDD for Philadelphia IAP; 1104 for Camden; 983 for McGuire AFB, NJ; 945 CDD fọr Wilmington AP; and $608 \mathrm{CDD}$ for.Wilkes Barre-Scranton. Long-term historical temperature distributions are also tabulated in NAVFAC P-88 (TM 5-785) for Newark IAP, McGuire AFB, Wilmington AP, and Wilkes Barre-Scranton, but not for NASWG, Philadelphia or Camden. The available data indicate annual base- 60 and base- 65 cooling load potentials as shown in Table 5.1.

From these data it is clear that Wilmington's climate is more (in terms of annual air-conditioning load). like that of Willow Grove than the climate of any of the other locations (except possibly distant McGuire AFB). The Wilmington climate was deemed sufficiently similar to be used as normal-year weather without further adjustment.

Ambient temperatures during the analysis period are compared to normal weather year ambient temperatures in Figure 5.1.

Based on the Wilmington climate data, normal-year cooling loads and energy use were extrapolated from the monitoring period by applying a cooling degree-day factor of 1.96 . The units are therefore expected to consume $370 \mathrm{MBtu}$ of gas and provide $225 \mathrm{MBtu}$ of cooling in a normal cooling season. The estimated normal-year heating energy use will be about $190 \mathrm{MBtu}$ of fuel. 
Table 5.1. Available Climate Data

\begin{tabular}{|l|c|c|c|}
\hline & $\begin{array}{c}\text { Base } \mathbf{6 5}^{\circ} \mathbf{F} \\
\mathbf{C D D}^{(\mathbf{a})}\end{array}$ & $\begin{array}{c}\text { Base }^{\mathbf{6}} \mathbf{5}^{\circ} \mathbf{F} \\
\mathbf{C D D}^{(\mathbf{b})}\end{array}$ & $\begin{array}{c}\text { Base }^{\mathbf{6}} \mathbf{}^{\circ} \mathbf{F} \\
\mathbf{C D D}^{(\mathbf{b})}\end{array}$ \\
\hline Willow Grove NAS & 946 & NA & NA \\
\hline Philadelphia IAP & 1104 & NA & NA \\
\hline Camden & 1104 & NA & NA \\
\hline Newark IAP & 1024 & 1168 & 1835 \\
\hline McGuire AFB & 983 & 1076 & 1778 \\
\hline Wilmington AP & 992 & 1154 & 1822 \\
\hline Wilkes Barre-Scranton & 608 & 798 & 1336 \\
\hline
\end{tabular}

(a) Based on mean of daily max/min temperatures, Chapter 5.0 of NAVFAC P-89 (TM 5-785).

(b) based on one-hour or three-hour temperature readings, Ch. 3 of NAVFAC P-89 (TM 5-785).

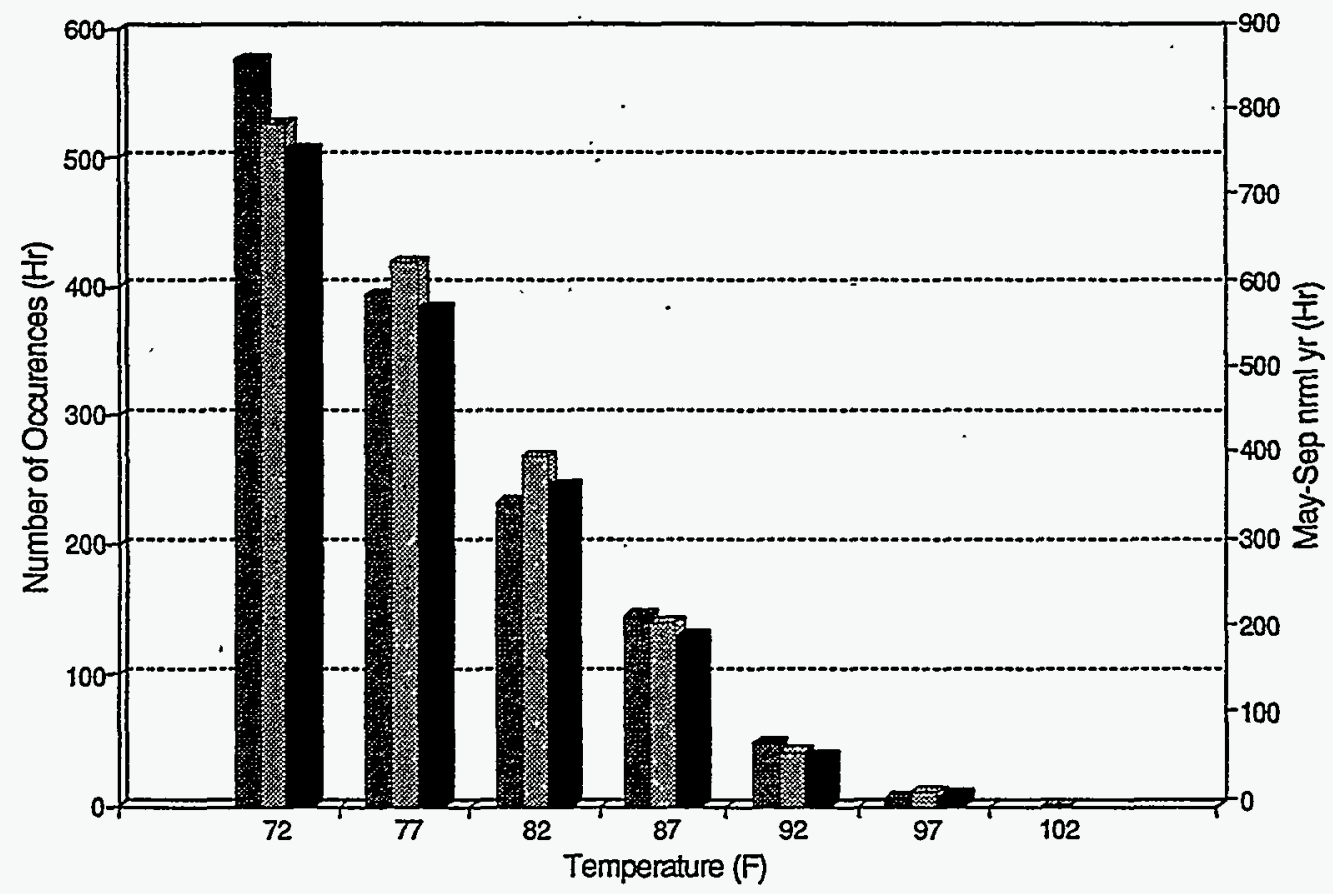

6/27-9/21 1992 Julsep nml yr May-Sep nml yr

Figure 5.1. Comparison of Normal-Year and 1992 Ambient Temperature Distributions 


\subsection{Operating Costs}

The annual operating cost for the base case (electric-powered units) consists of electric energy, demand, and ratchet penalty costs. The cost of compressor motor maintenance is assumed to be - negligible and the other maintenance costs (filter, damper, controls, refrigerant loop, and supply fan maintenance), which will be the same for both the gas- and electric-powered units, are estimated to be $\$ 200 /$ year. Primary heating energy costs are also assumed to be the same for the new technology as for the base case. The PECO Energy rate schedule (PECO Energy 1991) that applies to NASWG charges $\$ 0.0299$ per $\mathrm{kWh}$ and $\$ 23.70$ per monthly peak demand $\mathrm{kW}$. The minimum monthly demand charge is $80 \%$ of the maximum over the preceding eleven months. The load peak for the electricpowered units is assumed to coincide with the peak at the PECO Energy meter that measures all electrical energy supplied to NASWG.

The annual operating cost for the gas-powered units is considered to consist of natural gas purchases plus annual engine service of $\$ 400.00 / \mathrm{yr}$, plus the $\$ 200 / \mathrm{yr}$ cost of a conventional 15 -ton RTV. The PECO Energy natural gas rate schedule that applies to NASWG charges $\$ 6.50 / \mathrm{kcf}$ for the first 200 kcf purchased each month and $\$ 5.60$ per additional $\mathrm{kcf}$.

The normal-weather year energy requirements are shown, for the electric- and natural-gas-powered alternatives, in Figure 5.2. The monthly electric and gas numbers are in almost constant proportion because the electric motor and gas engine efficiencies are almost independent of shaft speed and load. Monthly peak 15 -minute demand was assumed to be $100 \%$ of connected load for all months with at least one hour at, or over, $80^{\circ} \mathrm{F}$ and to decrease linearly with peak hourly temperature to $60^{\circ} \mathrm{F}$.

The corresponding monthly energy costs are shown in Figure 5.3. The electric cost is almost double the gas cost in July and the cost difference is even larger in the other months. The distribution of monthly energy costs for the electric-powered alternative is shown in Figure 5.4. The figure shows that demand charges account for more than half, ratchet charges account for over $30 \%$, while energy charges account for less than $10 \%$ of the electric rooftop units' annual operating cost. 


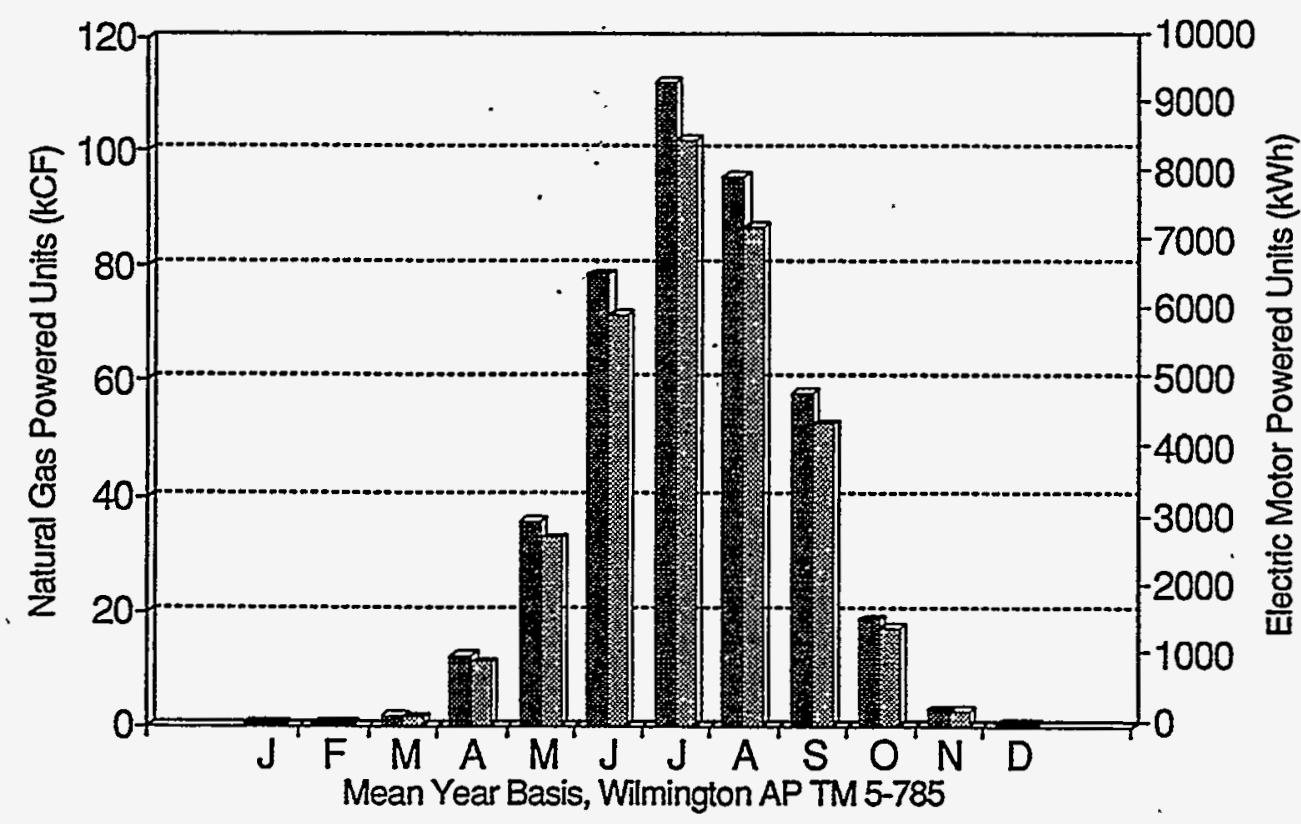

Electric Nat Gas

Figure 5.2. Energy Requirements for Electric and Natural Gas Alternatives

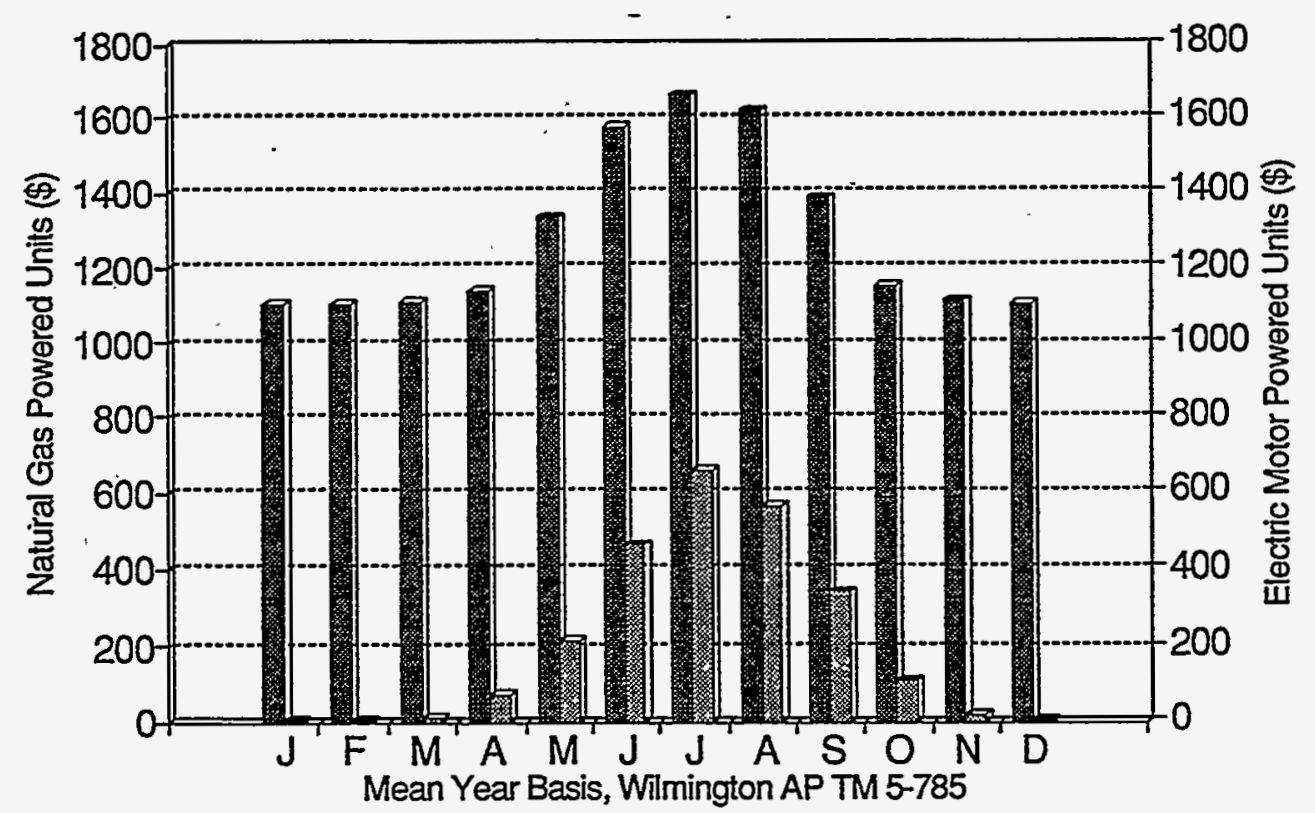

Nat. Gas

Figure 5.3. Monthly Energy Costs for Electric and Natural Gas Alternatives 


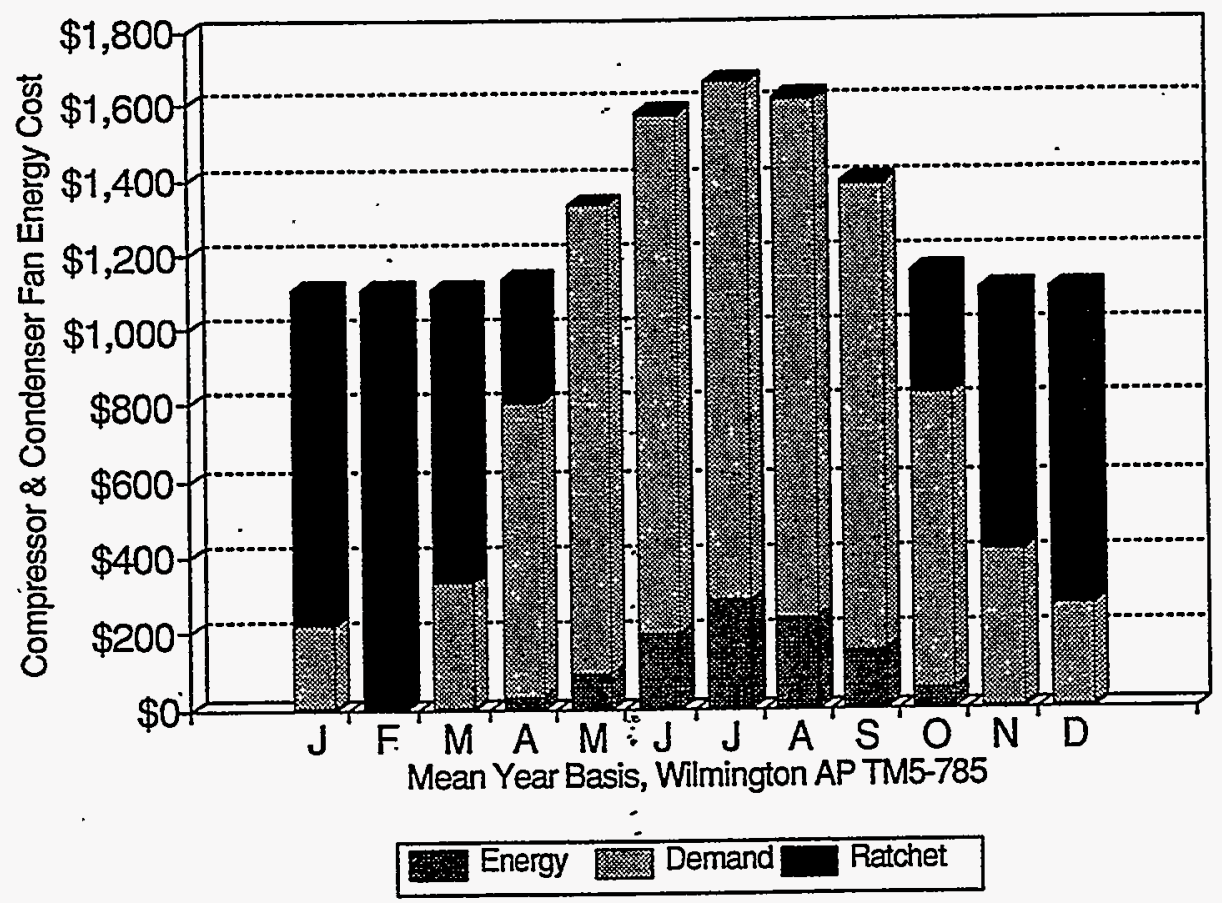

Figure 5.4. Distribution of Monthly Energy Costs for the Electric Alternative

\subsection{Life-Cycle Cost Comparison}

A life-cycle cost analysis was performed using the FEMP analysis program BLCC (NIST). The financial parameters for the cost study are as follows:

Analysis Type: Federal Analysis--Energy Conservation Projects

Study Period: 15 Years (1993 Through 2007)

Discount Rate: $4.0 \%$ Real (exclusive of general inflation)

The energy-related costs for the electric (base case) and gas-powered alternatives are shown in Table 5.2.

Table 5.2. Energy-Related Costs

\begin{tabular}{|l|c|c|c|c|}
\hline \multicolumn{1}{|c|}{ Energy Type } & Units/Year & $\begin{array}{c}\text { Price } \\
\text { (\$/Unit) }\end{array}$ & $\begin{array}{c}\text { Demand } \\
\text { Cost }\end{array}$ & $\begin{array}{c}\text { Total P.V. } \\
\text { Cost }\end{array}$ \\
\hline Electricity & 34,618 & $\$ 0.030$ & $\$ 14,379$ & $\$ 182,696$ \\
\hline Natural Gas & 3,875 & $\$ 0.634$ & $\$ 0$ & $\$ 29,114$ \\
\hline
\end{tabular}


The present value costs for the two alternatives are shown in Table 5.3.

Table 5.3. Comparison of Present-Value Costs

\begin{tabular}{|c|c|c|c|}
\hline . & $\begin{array}{l}\text { Base Case: } \\
\text { WGNAS_E }\end{array}$ & $\begin{array}{l}\text { Alternative: } \\
\text { WGNAS_NG }\end{array}$ & $\begin{array}{l}\text { Savings from } \\
\text { Alternative }\end{array}$ \\
\hline $\begin{array}{l}\text { Initial Investment Item(s): cash } \\
\text { requirements as of occupancy }\end{array}$ & $\$ 51,330$ & $\$ 77,972$ & $-\$ 26,642$ \\
\hline Subtotal & $\$ 51,330$ & $\$ 77,972$ & $-\$ 26,642$ \\
\hline $\begin{array}{l}\text { Future Cost Item(s): annual maintenance, } \\
\text { annual utility billings }\end{array}$ & $\begin{array}{r}\$ 2,780 \\
\$ 182,696\end{array}$ & $\begin{array}{r}\$ 8,339 \\
\$ 29,114\end{array}$ & $\begin{array}{r}-\$ 5,559 \\
\$ 153,582\end{array}$ \\
\hline Subtótal & $\$ 185,476$ & $\$ 37,453$ & $\$ 148,023$ \\
\hline Total P.V. Life-Cycle Cost & $\$ 236,806$ & $\$ 115,425$ & $\$ 121,381$ \\
\hline
\end{tabular}

The net savings for the gas-powered alternative is the difference between the present value of noninvestment savings, $\$ 148,023$, and the increased total investment of $\$ 26,642$. This gives a net savings, expressed as a present value, of $\$ 121,381$ for the gas-powered alternative. The savings-to-investment ratio is 5.56, assuming the previous electric units had to be replaced anyway at the time the TK units were installed. In cases where the existing electrical equipment is relatively new, the net savings-toinvestment ratio would be much less, but it is still favorable $(1.90)^{(a)}$ even for the hypothetical case of replacing brand new electric equipment, given PECO Energy's rate structure and the load distributions observed at the NASWG NEX.

One consideration in the decision to procure the subject technology is the first cost of the equipment versus operating costs. Since many facilities fund capital improvements from one budget and operation, service, and maintenance from another, the long-term savings have no practical benefit. In the above case for NASWG the long-term operating expense reduction of $\$ 148,023$ would not be considered, or even attainable, if a procurement decision based on lowest first cost were made. Note that the increased first cost is paid back in about two years.

Some utilities offer rebate programs and financing assistance that can help address the first cost issue. For instance, PECO Energy's Demand Side Management Program Plan proposes incentives for gas cooling of $\$ 300 / \mathrm{kW}$, or about $\$ 450 /$ ton, cooling capacity. This incentive, had it been in effect at

(a) $\underline{148,023}=1.898$, where $\$ 148,023$ is the net present value of future O\&M savings and $\$ 77,972$ is 77,972 the initial implementation cost for gas-powered equipment, assuming no recovery of the $\$ 51,330$ recently invested in brand new electric-powered air-conditioning equipment. 
the time of installation, would have resulted in about $\$ 13,500$ being available to NASWG to offset the additional $\$ 26,642$ for the Thermo King equipment. Where such demand side management or incentive programs exist, financial support for the additional first cost can be found. 


\subsection{Conclusions and Recommendations}

Based on the results of the NASWG demonstration, certain conclusions about the equipment per- formance can be drawn and then applied to the entire federal sector. In addition, recommendations for application of the equipment at other federal sites can be provided. Section 6.1 describes the savings potential at NASWG. The savings potential in the federal sector is estimated in Section 6.2. Conditions that should be considered in implementing this technology at other federal sites are presented in Section 6.3.

\subsection{Savings Potential at NASWG}

The annual energy cost is $\$ 2,450$ /yr to operate the compressors and condenser fans in the two TK units. This is based on the building loads and equipment performance measured during the 10week monitoring period during the summer of 1992 and weather data normalized to the full cooling season in a normal year as described in Section 4.0. The annual energy costs to operate the compressors and condenser fans in comparable electric-powered units would be $\$ 1,040 / \mathrm{yr}$ in energy charges and $\$ 14,380 / y r$ in demand and ratchet charges. Maintenance of the TK units is expected to cost $\$ 400 / y^{(a)}$ more than the maintenance of comparable electric-powered units.

The TK units will use about the same amount of source energy ${ }^{(b)}$ as comparable electric-powered units. The only real differences between the electric- and gas-powered units result from the operating characteristics of the electric motor or natural gas engine as a source of compressor shaft power. The service (level of comfort) provided by the two types of units is indistinguishable. ${ }^{(c)}$

(a) The estimate is based on engine maintenance only because refrigeration subsystem and air-side maintenance activities are the same as for electric motor driven units. According to GTC-1 Installation, Operation and Maintenance Manual, publication \#TK 40267-1, 1/93, page 11, one engine maintenance call per year is required for complete tune-up, renewal of filters, 40 quart oil change and engine winterization.

(b) Source energy is defined as total energy that must be supplied to the source power plant or regional gas transmission system to provide a specified end-use service. This definition considers transmission, distribution, and generation losses but does not consider extraction, processing and transmission losses outside the region of interest.

(c) The noise level of the units was not considered objectionable by the NASWG. No incremental effect of ozone depletion would be found since the TK unit uses R-22, an HCFC refrigerant which is common to electric rooftop equipment as well. A short-term reduction in fossil fuel emissions may result from replacement of electric power as the energy source by natural gas; however, in the long term central plant emissions are expected to be as low, per electric cooling ton-hr delivered, as the per-ton-hr emissions resulting from gas-powered air conditioners. 
The net savings for the gas-powered unit is the difference between the present value of non-investment savings, $\$ 148,023$, and the increased total investment of $\$ 26,642$. This gives a net savings, expressed as a present value, of $\$ 121,381$ for the gas-powered alternative over a 15-year life cycle. The net savings-to-investment ratio is 5.56 , assuming the previous electric units had to be replaced anyway at the time the TK units were installed. In cases where the existing electrical equipment is not worn out, the net savings-to-investment ratio would be less, but it is still attractive (1.88), even for the hypothetical case of replacing brand-new electric equipment, given the rate structure and load distributions at Willow Grove.

\subsection{Savings Potential in the Federal Sector}

Estimates of the aggregate cost-effective fuel-switchable capacity and present value of the resulting decrease in annual energy costs can be made given certain assumptions. The mix of existing cooling equipment and fraction for which replacement by the new technology is feasible must be assumed because the only numbers available for most federal sites are aggregate installed capacities. The annual energy consumption per unit installed capacity must also be estimated from available climate data. The quotient of annual full-load-equivalent operating time (FLE) and SEER gives one such estimate. A database of FLE (and other characteristics data) for 240 U.S. military installations has been compiled by Nemeth $(1993,1995)$. In this compilation FLE is estimated for a particular site by:

where

$$
\mathrm{FLE}[\mathrm{hr} / \mathrm{yr}]=\frac{24[\mathrm{hr} / \mathrm{day}] \times \mathrm{CDD}\left[{ }^{\circ} \mathrm{F}-\mathrm{day} / \mathrm{yr}\right]}{\mathrm{T}_{\mathrm{CE}}-\mathrm{T}_{\mathrm{Cl}}\left[^{\circ} \mathrm{F}\right]}
$$

$\mathrm{CDD}=$ cooling degree days with respect to a base temperature of $65^{\circ} \mathrm{F}$,

$T_{C E}=$ exterior design temperature, and

$\mathrm{T}_{\mathrm{Cl}}=$ interior design temperature.

The sites where the new technology is cost-effective may be identified by computing the net present value per unit capacity:

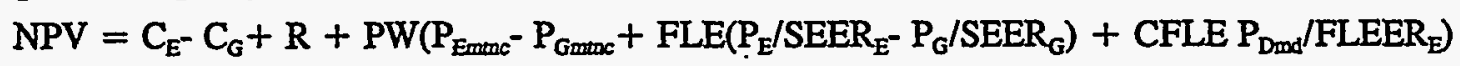
where

$C_{E}, C_{G}=$ first cost per unit capacity of conventional electric- and alternative gas-engine-driven units, $\mathbf{R}=$ utility rebate,

$\mathrm{P}_{\mathrm{Emnc}}, \mathrm{P}_{\mathrm{Gmmc}}=$ annualized maintenance costs, per unit capacity, of electric and gas units $\mathrm{PW}(\mathrm{x})=$ present worth of annually recurring cost $\mathrm{x}$ over a 15 -year period at $4 \%$ real discount rate, FLE $=$ full-load-equivalent operating time per year, $P_{E}, P_{G}=$ energy prices, adjusted for difference between fuel escalation and general inflation rates, SEER $_{E}$, SEER $_{G}=$ electric and gas equipment seasonal energy efficiencies,

CFLE = equivalent number of demand billing period coincident-full-load events per year,

$\mathrm{P}_{\mathrm{Dmd}}=$ electric demand price (per summer demand billing period)

FLEER $R_{E}=$ full-load energy efficiency of conventional electric-driven equipment. 
Note that the first cost to the owner may be modified by utility incentives in some cases. However, this effect is not considered here because of the large number of, and frequent changes in, utility incentive program. The effect of ratchet demand rates is also not considered because the ratchet parameters are not included in the database. Savings at sites where the per unit NPV is positive are evaluated by multiplying by the installed capacity of equipment eligible for replacement by the new technology. The site NPVs are summed to obtain total savings across all sites.

The results of this analysis indicate that the new technology is life-cycle cost-effective at 10 of the 240 military sites. These sites represent about $6 \%$ of the cooling capacity reported for all sites and over $5 \%$ of the aggregate annual cooling load, as estimated by the above formulas, for all sites.

Assuming that gas-engine-driven cooling equipment with performance and price characteristics similar to the 15-ton rooftop units is made available in a range of sizes ( 2 to 2,000 tons) and configurations (chillers, split systems, package units), the aggregate potential NPV is over $\$ 100$ million and the fuel switch results in about $396,000 \mathrm{MWh} / \mathrm{yr}$ of electric energy use being displaced by $5,628,000 \mathrm{MBtu} / \mathrm{yr}$ of natural gas consumption. These numbers can be extrapolated to the entire stock of federally owned buildings if it is assumed that the distributions of building type, installed cooling capacity, climate, and utility rates for the entire federal sector are well represented by Nemeth's 240 military sites. For the entire federally owned building stock, the potential NPV and energy savings are about twice as large.

\subsection{Conditions for Implementation}

In the analysis of the retrofit economics for other sites, it is important to determine-by simulation or by monitoring existing equipment with simple run-hour clocks ${ }^{(a)}$ and logs-the distribution of part-load hours for a typical cooling season. This is imperative where the gas-powered alternative is expected to be only marginally attractive or where there is reason to believe that the existing equipment is significantly oversized or undersized. A feasibility study can then be completed using the normal year energy analysis developed and presented in Section $\mathbf{5 . 2}$ of this report.

A preliminary sense of the technology's feasibility can be gained using an analysis similar to the federal sector potential analysis described in the previous section. By defining an end-use specific blended electric rate, the analysis can be generalized to include the common demand ratchet rate structures. To avoid confusion with the site-wide blended rate we will refer to this end-use-specific blended rate as the marginal electric cooling rate, $P_{\text {MEC. }}$

(a) A run-hour clock connected to each cooling stage control line will give a good indication of part load distribution. The readings should be logged at least-weekly. A daily log of the readings, together with daily outdoor maximum and minimum temperature, will facilitate extrapolation of the part-load distribution to a normal-weather year. 
This rate is defined as follows:

$$
P_{M E C}=P_{E}+P_{E, D m d} \frac{C F L E}{\text { FLE }} \frac{S_{\text {FEER }}}{\text { FEER }_{E}}
$$

The reduction in annual demand and ratchet charges effected by the switch from electric- to gaspowered cooling equipment can also be estimated using a simple approximation (Sohn 1992) in which cooling season demand charges are given by

$$
\mathrm{N}_{\operatorname{CSM}} \mathrm{P}_{\mathrm{Dmd}}
$$

and the ratchet penalty is given by

$$
F_{\text {ratchet }}\left(12-N_{C S M}\right) P_{\text {Dod }}
$$

where

$\left.N_{C S M}=L N_{C S D} / 30.67+1\right\lrcorner$ is the number of cooling season months,

$\mathrm{N}_{\text {CSD }}=$ number of cooling season days from the REEP.database or, if reliable load-specific data is available, from local experience,

$\mathrm{LX}_{\lrcorner}$is the integer part of $\mathrm{x}$, and

$F_{\text {ratchet }}$ is the ratchet penalty ( 0.5 to 0.9 for most capacity-short utilities, 0 otherwise).

With the foregoing parameters it is possible to estimate NPV based on three variables (FLE, $P_{0}$, $P_{M E C}$ representing climate and gas and electric rates. It is also possible to determine the value of any one parameter that is needed to make the new technology cost-effective given the other two. This relationship is presented in Figure 6.1.

The sites used in the Section 6.2 analysis are also shown in Figure 6.1 to give an indication of how a rate change or rebate will affect the technology's federal-sector potential. Two points are shown for each site where gas is available. (Thirty-five of the 240 sites do not have gas, and the database therefore gives a gas price of 0 ; these sites are not represented in the figure.) Each " $\square$ " on the plot indicates the existing marginal electric cooling cost at a site. Vertically aligned with each " $\square$ " is an " $x$ " indicating the marginal electrical cost that is needed to make the new technology cost-effective at the site. In most cases the " $x$ " is above its corresponding " $\square$ " and the vertical separation is the increase in $P_{M E C}$ needed to justify a change to gas-powered cooling equipment. In the 10 cases with a positive site NPV, the " $\mathrm{x}$ "s are below their corresponding " $\square$ "s.

Note that one representative value of FLE was used for each site in the Section 6.2 analysis. Different buildings at a given site will, in reality, exhibit different annual FLE runtime characteristics, so a site for which the preliminary analysis shows the cooling technology to be "not quite" cost effective is likely to have a number of buildings where the technology is cost effective. Building or zone-specific feasibility analyses, e.g., the FEDS program, should be performed in such cases.

In addition to the strictly economic conditions, one must consider practical constraints on the technology. Foremost among these is the need for a well-organized maintenance provider. The maintenance requirements of the technology are not burdensome, but the possible consequences of maintenance errors or omissions are more serious than for comparable electric-driven cooling equipment. Noise and vibration must also be considered because both are considerably greater than. those of comparable electric-driven equipment. 


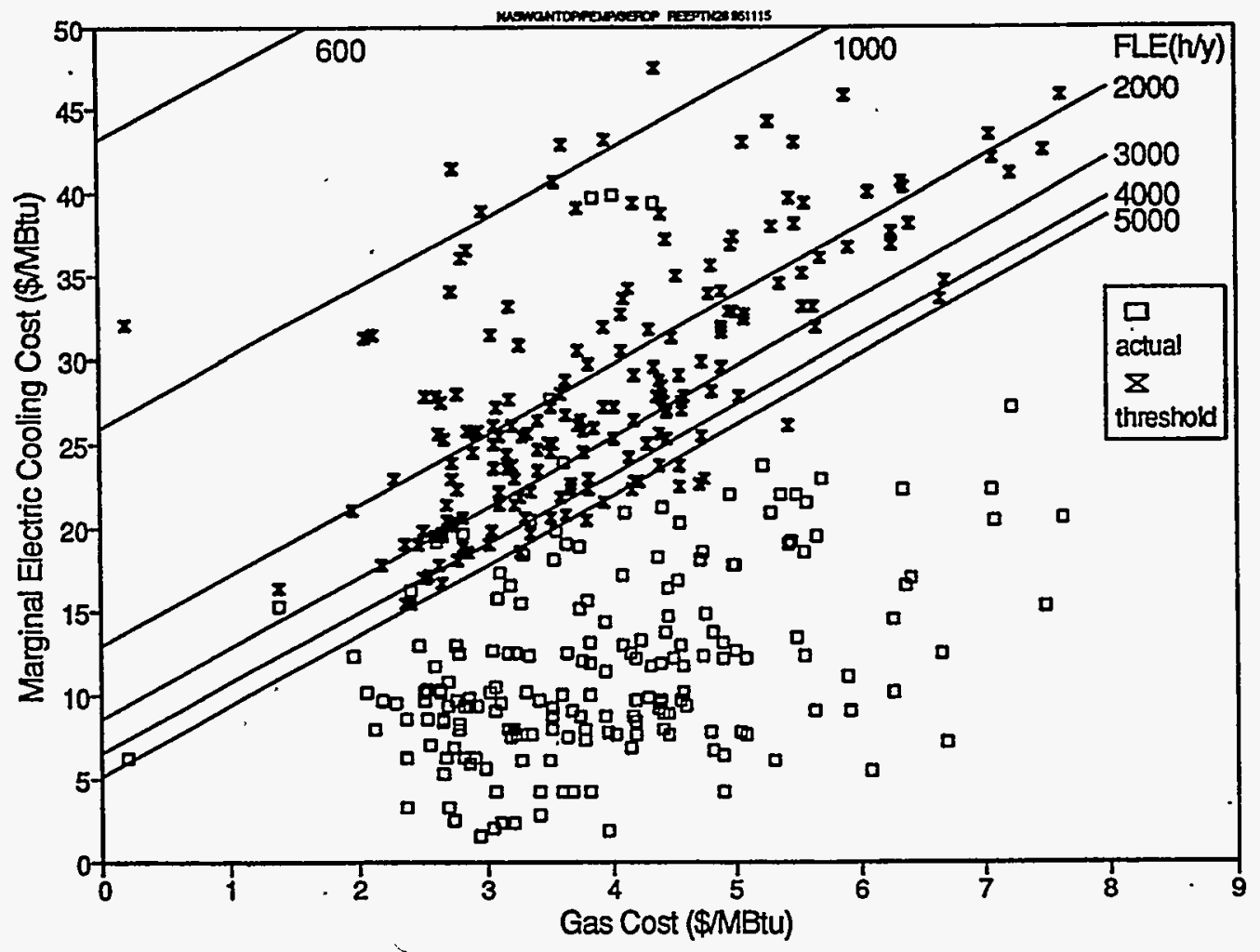

Figure 6.1. LCC-Effectiveness Thresholds for the Gas-Cooling Technology Based on the REEP Data for 240 Military Sites

The location of the equipment in relation to air intakes must be considered because of the high carbon dioxide and water vapor content of the engine exhaust stream. The heat rejection load must be considered in densely populated or temperature-sensitive areas. The new technology's heat rejection load is about. $50 \%$ greater than that of comparable electric-driven technologies. Lastly, a responsible building occupant should be assigned to act as the point of contact for thermal comfort issues. This person should be briefed on the nature of the equipment, importance of correct and consistent thermostat schedule, and the need to promptly report unsatisfactory or unusual system behavior.

In summary, the new technology is generally cost-effective at sites where marginal electricity cost (per MBtu at the meter) is more than four times the marginal gas cost (per MBtu at the meter) and annual full-load-equivalent (AFLE) cooling hours exceed 2,000. This rule-of-thumb was derived from the analysis of sites with marginal gas prices of $\$ 2.20$ to $\$ 7.30$ per MBtu. Applications with fewer AFLE cooling hours will be cost effective at correspondingly higher electric-to-gas price ratios. 


\subsection{References}

AGAL, 1990. Combustion Analysis of TK Units in CA, $N M, M N \& O H$. American Gas Association - Laboratory, Cleveland, Ohio.

ANSI/ARI, 1986. Commercial and Industrial Unitary Air-Conditioning Equipment, ANSI/ARI 36086, Air-conditioning and Refrigeration Institute, Arlington, Virginia.

Armstrong, P. R., and D. R. Conover. May 1993. Performance and Evaluation of Gas Engine Driven Rooftop Air Conditioning Equipment at the Willow Grove (PA) Naval Air Station, Interim Report - 1992 Cooling Season. PNL-8677, Pacific Northwest Laboratory, Richland, Washington.

ASHRAE, 1991, "A Guide for Analyzing and Reporting Energy Use and Characteristics of Commercial Buildings," prepared for PNL under contract 001011-A-A2, May, 1991.

ASHRAE, 1987, "An Assessment of the Energy Audit Process in Commercial Buildings," SP-56, December, 1987.

ASHRAE, 1989, Handbook of Fundamentals; American Society of Heating, Refrigeration and AirConditioning Engineers, Atlanta, Georgia.

Balcomb, J. D., et al, Passive Solar Design Handbook, Volume-II, DOE/CS-0127/2 (January 1980).

EOGC, 1994. Hercules G 1600 Emissions Potential: Ohio EPA Exempt Source Filing, East Ohio Gas Company, eog/mdr 5-16-94.

Falvey, T. P., Natural Gas Cooling at NAS WILGRO. Phase Two-Building 605, Base Exchange, Public Works Services Directorate, Northern Division, Naval Facilities Engineering Command, Philadelphia, Pennsylvania (May 1990).

Mathews, W. F. 1992. "Chill out with another opinion of engine-driven chillers," letter to the editor, Engineered Systems, November/December 1992.

NAVFAC P-89, Engineering Weather Data (aka USAF TM-785) 1978, Washington, D.C.

Nemeth, R. J., D. E. Fornier, and L. A. Edgar. 1993. Renewables and Energy Efficiency Planning (and accompanying database), U.S. Army Construction Engineering Research Laboratory, Champaign, Illinois.

Nemeth, R. J., D. E. Fornier, and L. A. Edgar. 1995. Renewable and Energy Efficiency Planning-REEP Database, version 2.6, U.S. Army Construction Engineering Research Laboratory, Champaign, Illinois. 
NIST, Comprehensive Guide for Least-Cost Energy Decisions, National Institute of Standards and Technology, NBS Special Publication 709, 1987, USDOC, Gaithersburg, Maryland.

NIST, Life-Cycle Costing Manual, National Institute of Standards and Technology, NBS Handbook 135, 1987, USDOC, Gaithersburg, Maryland.

NIST, Energy Prices and Discount Factors for Life-Cycle Cost Analysis 1993, National Institute of Standards and Technology, NIST Interagency Report 85-3273-7 (Annual Supplement to Handbook 135), 1992, USDOC, Gaithersburg, Maryland.

NIST, $A$ User's Guide to the Federal Building Life-Cycle Cost (FBLCC) Computer Program, National Institute of Standards and Technology, NBS Technical Note 1222, 1986, USDOC, Gaithersburg, Maryland.

Philadelphia Electric Company, Demand Side Management Program Plan, February 28, 1991, Before the Pennsylvania Public Utilities Commission, Docket No. I-900005.

Sohn, C. W., and J. H. Kim. 1992. STOFEAS: A CERL Computer Program for Estimating the Economic Feasibility of Storage Cooling Systems. USACERL Report FE-93/12, December 1992.

SWRI, 1988. Natural Gas Engine Performance Tests, Southwest Research for GRI.

TM-785 (see NAVFAC P-89).

\section{Site Data}

Monthly NEX gas meter readings

Monthly NEX electric meter readings

Building characteristics data provided by Jim Edmond in ASHRAE (1991) format.

Daily maximum/minimum temperatures from NASWG site weather station for $6 / 92$ through $10 / 92$.

Thermo King, 1990. Specification, Thermo King Corp. (draft-no publication \#).

Thermo King, 1991. Thermo-King GTC-1, Thermo King Corp. publication \#TK 30058-2 (4-91).

Thermo King, 1993. GTC-1. Installation, Operation and Maintenance Manual, Thermo King Corp. publication \#TK 40267-1 (1-93). 


\section{Appendix A}

Summary of Activity Leading to the Cooperative R\&D Agreement (CRADA) and the Joint Statement of Work (JSOW) 


\section{Appendix A}

\section{Summary of Activity Leading to the Cooperative R\&D Agreement (CRADA) and the Joint Statement of Work (JSOW)}

The federal government is the largest single energy consumer in the United States with consumption estimated to be nearly 1.5 quads $\left(1\right.$ quad $=10^{15} \mathrm{Btu}$ ) and cost valued at nearly $\$ 10$ billion annually. The Federal Energy Management Program (FEMP) supports efforts to reduce energy use and associated expenditures within the federal sector. One such effort, the New Technology Demonstration Program (formerly the Test Bed Demonstration Program), seeks to evaluate new energy- saving U.S. technologies and secure their more timely adoption by the federal government.

Each year the federal government purchases equipment and products through a procurement process that may not readily recognize or accommodate new technologies. In addition, new technologies are rarely purchased and installed until they have been proven through private-sector use. This results in unnecessary federal energy use and operating cost between the time that the technology is commercially available and when it has been "proven" to, and recognized by, federal decision makers.

The New Technology Demonstration Program aims to demonstrate the field performance of selected technologies implemented within the Federal sector and transfer that information to federal decision makers. These "hands on" data provide the federal decision maker with the information needed to justify procurement of the technology in a more timely fashion. This leads to accelerated energy savings and associated environmental benefits. In addition, because the program is limited to U.S. technologies, the U.S. position in the global marketplace may be enhanced.

The program works by using available FEMP resources as leverage to secure public and private interest in jointly evaluating the performance of a new technology. Through a Cooperative Research and Development Agreement (CRADA) a partnership can be created that allows federal and non-federal interests to jointly sponsor such efforts. These partnerships usually involve the manufacturer of the selected technology, a federal site, the utility serving the site, a technology-related research institute, a trade association, and other interested parties. All participants perform certain activities, at their own cost, within the larger program to install and evaluate the technology. This creates a cooperative atmosphere and affords information sharing and economies of scale that might not occur . otherwise. 
Recent initiatives within the federal government have focused on the use of natural gas for both economic and environmental reasons. It is therefore fitting that the technology selected for evaluation in the first new technology demonstration, and the subject of this report, is natural-gas-engine-driven cooling equipment.

The project began with the solicitation of interested parties willing to participate in the installation and evaluation of gas cooling technologies. Responses to the solicitation were received from manufacturers and utilities and communications were initiated to explore potential demonstration arrangements. In addition a search was undertaken to identify a suitable federal site within the service areas of those responding utilities. During the last half of 1991 and in early 1992 the plans of many of the respondents changed, leaving one manufacturer and three utilities still interested in participating in the project.

The equipment offered by the one manufacturer, Thermo King Corporation, was a 15-ton naturalgas-engine-driven rooftop air-conditioning unit. The unit is air cooled and serves a single zone for both heating and cooling. It is factory assembled with R-22 (an HCFC refrigerant) and requires single point connections of electrical power and natural gas. The unit's cooling capacity is 190,000 Btuh at ARI Standard 360 rating conditions. The unit's heating capacity is $216,000 \mathrm{Btuh}$ output at 265,000 Btuh input. Variable engine speed and cylinder unloading allow for cooling operation in 4 stages.

All three utilities still interested in participating in the project were asked in early 1992 to help identify a federal site and.building that would be suitable for installation and evaluation of the cooling equipment. Numerous buildings were suggested, including historical buildings associated with Independence National Historic Park in Philadelphia, the James E. Carter Library in Atlanta, and postal service facilities in Baltimore. PECO Energy, one of the three interested utilities, located a naval facility within its service area that had recently (fall 1991) installed two of the Thermo King units. This provided an opportunity to more quickly implement the first demonstration, which became critical with the 1992 cooling season approaching. Efforts were initiated to formalize a CRADA among the participating organizations for a demonstration project at the Naval Air Station, Willow Grove, Pennsylivania (NASWG).

A site visit was made to the Naval Air Station at Willow Grove Pennsylvania where two units were installed to serve a retail facility. Discussions were also conducted with other interested parties who had responded to the solicitation: These included the American Gas Cooling Center, PECO Energy, and the Thermo King Corporation. Based on an evaluation of the building, utility costs, and past building performance, it was determined that the installation offered a good opportunity to evaluate the performance of the subject technology.

A CRADA, which included a joint statement of work, was developed and forwarded to all parties for review and evaluation. Subsequent to signing the agreement, work was.initiated on planning the evaluation methodology and installing the data acquisition system that would monitor and report on 
equipment and building operation, and climatic conditions. As part of the agreement the American Gas Association Laboratories, who had performed similar efforts on the equipment at other non-federal installations, was tasked to design the data acquisition system on behalf of PECO Energy and AGCC. At the beginning of the 1992 cooling season the data acquisition system was installed and commissioned. Data on the operation of the units were secured during the 1992 cooling season and testing was continued during 1993 to observe heating season performance.

An addendum to the CRADA was signed by the participants in June 1993 to continue monitoring through the 1993 cooling season in order to test some control improvements proposed in the May 1993 interim report (Armstrong and Conover 1993). These improvements involved coordinating the operation of the two RTUs and required installation of a duct with a backdraft damper to connect the two distribution systems. NASWG committed to the duct installation but the work was never completed. 


\section{Appendix B}

Glossary of Terms and Abbreviations 


\section{Appendix B}

\section{Glossary of Terms and Abbreviations}

AAFES

AGA

AGCC

AGAL

AP

balance point

BLCC

Btu

Btuh

Btu/scf

CBECS

CDD

cfm
Army/Air Force Exchange Service-A DoD agency that owns and operates grocery, dry goods/retail, service station, mini-mart, and related facilities on U.S. military bases

American Gas Association

American Gas Cooling Center

American Gas Association Laboratory

airport weather station

mean daily temperature above which a daily cooling load is observed; the $\mathrm{x}$ intercept of the best linear fit to the daily cooling load versus mean daily temperature plot

the FEMP/DOC/NIST computer program for calculating Building Life-Cycle Costs of alternative investments that affect energy use; the program uses the energy escalation and cost of money rates specified in federal regulations

British thermal unit

Btu per hour

heat content of a cubic foot of gaseous fuel at standard conditions

Commercial Building Energy Consumption Survey-a survey conducted by DOE's Energy Information Agency and the title under which the survey results are reported

cooling degree days-the sum of all positive values of $\left(T-T_{\text {base }}\right)$ in the month, year, or other period of interest, where $T$ is the mean daily temperature and $\mathrm{T}_{\text {base }}$ is the cooling degree-day base

cubic foot per minute 
CDD base

condenser

COP

CRADA

$\mathrm{C} 1, \mathrm{C} 2, \mathrm{C} 3, \mathrm{C} 4$

DAS

degree-day

degree-day base

demand charge

desuperheater

discharge

DoD

DOC

DX

evaporator the temperature upon which a cooling energy calculation is based; see CDD

a heat exchanger in which a refrigerant is condensed by rejecting heat to another fluid, such as ambient air or cooling tower water, which has a lower temperature than the saturation temperature of the refrigerant

coefficient of performance-the ratio of cooling effect to input energy required to deliver the effect

\section{Cooperative Research and Development Agreement}

cooling stage designations where $\mathrm{Cl}$ refers to the lowest cooling rate and $\mathrm{C4}$ to the highest cooling rate (nominal capacity) of the machine

data acquisition system

a measure of the temperature distribution of a climate obtained by taking the time integral of the difference between temperature and base temperature whenever that difference is positive (CDD) or negative (HDD)

the reference temperature (most commonly $65^{\circ} \mathrm{F}$ ) used in a degree day calculation

a charge based on the utility customer's peak 15-minute electric load during the billing month

a heat exchanger (which may be part of the condenser) used to cool hot refrigerant vapor after it leaves the compressor

pertaining to the compressor outlet port or to refrigerant conditions at the compressor outlet port

Department of Defensce

Department of Commerce

direct expansion-a common method of space cooling in which the refrigerant expands inside the tubes of a heat exchanger, the outside surfaces of which are directly exposed to the air stream

a heat exchanger in which a refrigerant is boiled, thus extracting heat from another fluid, such as air, water or brine 
Federal Energy Management Program-the umbrella program under which the New Technology Demonstration Program operates

HCFC

hydrogenated chloroflourocarbon-a refrigerant that has low impact (compared to the non-hydrogenated CFC compounds) on the earth's atmospheric ozone, but which will eventually be replaced by refrigerants with even lower impact

HDD heating degree days-the sum of all positive values of $\left(T_{\text {base }}-T\right)$ in the month, year, or other period of interest, where $T$ is the mean daily temperature and $T_{\text {base }}$ is the heating degree-day base.

HDD base

the temperature upon which a heating energy calculation is based; see HDD

HHV

higher heating value-includes the latent heat of water vapor produced in the combustion of a fuel

hp

HVAC

horsepower-a measure of shaft (output) power and, in the case of motors, of electrical (input) power

$\mathrm{H} 1, \mathrm{H} 2$

heating, ventilating and air conditioning

heating stage designations where $\mathrm{H} 1$ refers to the lowest heating rate and $\mathrm{H} 2$ refers to the highest heating rate (corresponding to the nominal capacity) of a heating or heating unit

IAP

international airport weather station

IC engine

internal combustion engine

IPLV

integrated part-load value-a seasonal average COP or efficiency or total energy use obtained by convolution (integral of the product) of an HVAC unit's part-load COP, efficiency, or input power function with the load distribution function

JSOW

joint statement of work

$\mathrm{kcf}$

thousand cubic feet

$\mathrm{kWh}$

kilowatt-hour 
LCC

lbf

Ibm

MBtu

multi-zone RTU

NAS

NASWG

NAVFAC

net present

value (NPV)

NEX

NIST

NTDP

O\&M

PECO Energy

PNNL life-cycle cost-the total cost to own and operate a building (or other tangible property) -including cost of money, periodic and aperiodic maintenance and equipment replacement costs, energy escalation rates and salvage valueexpressed (usually) as a present value (PVLCC) or annualized value

pound force-a measure of force, in the English system, equal to the force required to accelerate one pound mass at $32.2 \mathrm{ft} / \mathrm{s}^{2}$

pound mass - a measure of mass (not weight) in the English system.

million British thermal units

a rooftop HVAC unit that provides variable supply air flow rates to a distribution system that has dampers or other means of controlling flow independently to two or more zones

Naval Air Station

Naval Air Station at Willow Grove, Pennsylvania

Naval Facilities Engineering Command

the difference between the PVLCC of the base case facility, system or component and the PVLCC of a given alternative facility, system or component

Navy exchange-a dry goods retail store, operated by AAFES, serving military personnel and dependents; aka post exchange $(\mathrm{PX})$ on Army bases

National Institute for Science and Technology $-\mathrm{a}$ DOC laboratory and developer of the FEMP life-cycle cost methodology and computer program

New Technology Demonstration Program

operation and maintenance, including all energy costs and operator labor, as well as maintenance labor and materials

known as Philadelphia Electric Company (PECO) prior to 1993

Pacific Northwest National Laboratory-lead laboratory for the FEMP New Technology Demonstration Program 
PV

PVLCC

ratchet chárge

RTU

savings to

investment

ratio (SIR)

source energy

subcool

suction

superheat

TK

ton present value-the value of future expense(s) or income(s), which is determined by the time-value of money.

present value life-cycle cost-see LCC

a monthly charge based on the utility customer's highest monthly demand in the preceding 12 months

rooftop unit-a HVAC unit located outside the building envelope that provides conditioned air to the distribution system via a roof penetration

the difference between the PV O\&M costs of the base case and the PV O\&M costs of a given alternative divided by the difference in their initial costs; thus an SIR of $>1$ corresponds to a positive NPV

the amount of energy input to a power plant (electricity) or energy input to a regional gas transmission system (natural gas) required to provide a given amount of energy at the customer's meter

to cool a liquid (e.g., refrigerant) below its saturation temperature

pertaining to the compressor inlet port or to refrigerant conditions at the compressor inlet port

to heat a gas (e.g., refrigerant) above its saturation (condensing) temperature

Thermo King Corporation-developer and manufacturer of the gas IC engine driven air-conditioning units demonstrated in this project

measure of refrigeration or cooling plant capacity equal to 12,000 Btuh 


\section{Distribution}

Number of

Copies

\section{Offsite}

12 DOE/Office of Scientific and Technical Information

18 Federal Energy Management Program U.S. Department of Energy 1000 Independence Avenue SW Washington, DC 20585 ATTN: Dean McCauley (EE-92)(15) Mark Ginsberg (EE-90)

Jim Brodrick (CE-422)

V. Petrolatti (IHEM)

4 Linda Applestein

PECO Energy 2301 Market St.

Philadelphia, PA 19101-8699

Ed Reed

AGCC

1515 Wilson Blvd

Arlington, VA 22209

Rick Szczepanski

ASL Refrigeration

95 Pond Rd.

Northhampton, PA 18067

3 - Public Works Dept. Bldg. 78

U.S. Naval Air Station

Willow Grove, PA 19090-5010

ATTN: Jim Edmond

Commander Mike Strand

Terry Falvey, NAVFAC.
Number of

Copies

2 Trico Energy Systems

2 Apple Tree Sq. Suite 335

Minneapolis, MN 55425

ATTN: Bob Ellis

Steve Lewis

2 Gas Research Institute

8600 West Bryn Mawr Avenue

Chicago, II 60631

ATTN: Bill Dolan

John Brogan

Daryl Matsui

NFESC Code 22

560 Center Dr.

Port Hueneme, CA 93043

Maj. Rich Durab CNRF

Naval Reserve Energy Programs

4400 Dauphine St.

New Orleans, LA 70146-5000

William Brown

U.S. Army CERL

2902 Newmark Drive

Champaign, Ill 61826-9005

ATTN: CECER-UL-U

Wm. Kaplan

USDOE Support Office

1421 Cherry St., 10th floor

Philadelphia, PA 19102

2 Pennsylvania Energy Office

116 Pine St.

Harrisburg, PA 17101-1227

ATTN: James Saḍa

Darlene Crawford 
Number of

Copies

$\underline{\text { Onsite }}$

DOE Richland Operations Office

J. P. Neath (K8-50)

27 Pacific Northwest National Laboratory

P. R. Armstrong (K5-20) (2)

D. R. Conover (BWO)

R. T. Dahowski (K8-17)

J. A. Dirks (K8-17)

D. R. Dixon (K8-17)

D. L. Hadley (K5-16)
Number of

Copies

W. D. Hunt (BWO)

L. D. Kannberg (K5-20)

S. Katipamula (K5-16) (2)

J. D. Miller (K5-20)

G. B. Parker (K8-17)

S. A. Parker (K5-08)

D. R. Payson (K7-90)

E. E. Richman (K5-16)

W. F. Sandusky (K5-08)

S. A. Shankle (K8-17)

M. K. Walker (BWO)

D. W. Winiarski (K5-08)

Information Release (7) 